\title{
Programa de participação nos resultados e comprometimento organizacional: um estudo em uma cooperativa de crédito
}

\section{Profit sharing program and organizational commitment: a study in a credit union}

\author{
Jucelia Appio Frizon', Ivan Binsfeld" \\ ' Universidade Estadual do Oeste do Paraná - UNIOESTE. juceliaappio@yahoo.com.br \\ "Universidade Estadual do Oeste do Paraná - UNIOESTE. binsfeld.ivan@gmail.com
}

\section{RESUMO}

Mudanças na gestão estratégica de pessoas impulsionaram processos mais flexíveis possibilitando às organizações implantarem instrumentos que contribuíam para elevar o comprometimento dos colaboradores. Por meio da abordagem quali-quanti este estudo buscou analisar se o Programa de Participação nos Resultados (PPR) está atrelado ao comprometimento organizacional na Cooperativa de Crédito Cresol Baser. A análise de regressão revelou que o PPR atua como um fator de comprometimento instrumental/calculativo (Beta=0,315 e sig=,046), evidenciando que os colaboradores se comprometem com a instituição ao constatar que serão recompensados pelo seu desempenho. As dimensões normativo e afetivo/atitudinal não tiveram significância relativa no teste de regressão múltipla. A análise, na fase qualitativa, evidencia que o PPR impacta no comprometimento dos colaboradores com a instituição, embora haja outros fatores que influenciam no comprometimento organizacional, como a gestão do clima organizacional, sistemas de reconhecimento, programas de treinamento, gestão de carreira e avaliação de desempenho.

Palavras-chave: gestão estratégica de pessoas. comprometimento instrumental/calculativo. cooperativa de crédito cresol baser. 


\section{ABSTRACT}

Changes in the strategic management of people led to more flexible processes, allowing organizations to implement instruments that contributed to increase employee commitment. Through the qualiquanti approach, this study sought to analyze whether the Profit Sharing Program (PSP) is linked to organizational commitment at credit union Cresol Baser. The regression analysis revealed that the PSP acts as an instrumental / calculative commitment factor (Beta $=0.315$ and Sig =,046), showing that employees are committed to the institution when they realize they will be rewarded for their performance. The normative and affective / attitudinal dimensions had no relative significance in the multiple regression test. The analysis, in the qualitative phase, shows that the PSP impacts the employees' commitment to the institution, although there are other factors that influence organizational commitment, such as the management of the organizational climate, recognition systems, training programs, career management and evaluation of performance.

Keywords: strategic management of people. instrumental /calculative commitment. credit union cresol baser.

\section{INTRODUÇÃO}

A Administração de Recursos Humanos, atualmente chamada de Gestão de Pessoas, é a área em que o profissional atua como criador de meios que avaliam as pessoas em vários parâmetros a fim de adquirir informações que possam dar alguma indicação sobre o perfil e caráter do indivíduo (FRANCO, 2008).

De acordo com Vergara (2003) o princípio da gestão de pessoas é integrar a empresa e as pessoas, pois uma depende da outra. As pessoas dependem da empresa para atingirem seus propósitos e a entidade necessita das pessoas para alcançar suas metas e objetivos.

Em meados dos anos 90, no Brasil, houve inúmeras mudanças relacionadas aos sindicatos, governo, empresa e o trabalhador. Essas mudanças impulsionaram uma nova forma de interação, a qual possibilitou uma maior flexibilidade e abertura para que as organizações implementassem novos programas relacionados a gestão organizacional. Para esse período, destacou-se a implementação de programas de remuneração variável, os quais tornaram-se uma alternativa de conciliação dos interesses entre a organização e colaborador (STONER; FREEMAN, 1995). 
Bohlander, Snell e Sherman (2003) defendem que entre a integração entre empresa e trabalhador, destaca-se a remuneração direta sendo esta a que engloba o salário, incentivos, comissões e bonificações. Seguindo essa linha, Milkovich e Boudreau (2009) contemplam que as remunerações diretas atuam como importante ferramenta que gera satisfação e instiga a motivação e o comprometimento, melhorando o desempenho dos colaboradores, ocasionando a busca por melhores resultados dentro da empresa.

Para que a entidade consiga atingir seus objetivos Becker e Ruas (1997) fomentam a ideia de que os colaboradores devem ser comprometidos com os objetivos da organização. Uma das formas de se alcançar o comprometimento dos colaboradores é oferecer recompensas por participação, onde o trabalhador ao buscar a recompensa acaba ajudando a empresa a alcançar seu objetivo.

Nesta linha de entendimento, uma estratégia crescente nas organizações refere-se ao Programa de Participação dos Resultados (PPR), neste os colaboradores são premiados por cumprirem com as metas e os planos traçados pela direção. Esses programas atuam como ferramenta que eleva o comprometimento e a motivação por parte dos colaboradores (ÁLVARES, 1999).

Essa temática vem sendo estudada internacionalmente, por exemplo, os estudos de Mowday et al. (1982), Defourney et al. (1985), Jones e Pliskin (1988), Benner e Jones (1995), Poutsma, Hendrickx e Huijgen (2003) e Farzan et al. (2008) e nacionalmente por autores como, Bassi (1995), Becker e Ruas (1997), Marinakis (1997), Becker (1998), Álvares (1999), Costa (2000), Medeiros e Heidemann (2000), Alves (2002), Brondani e Silva (2003), Corrêa e Lima (2006), Oliveira e Superti (2006), Milkovich e Boudreau (2009), Motta (2009). Esses autores possuem estudos relacionados ao PPR, os quais estão voltados em analisar como essas políticas podem 
auxiliar no aumento do comprometimento e desempenho por parte dos colaboradores.

A tendência para que as organizações adotem os programas de PPR se dá pelo fato de que a organização busca aumentar a motivação e o comprometimento de seus colaboradores com intuito de aumentar os índices de produtividade, participação e novas ideias. Dessa forma, as empresas vêm criando alternativas de remuneração variável aliada ao papel do comprometimento dos colaboradores (MOTTA, 2009).

Segundo Oliveira (2014) é crescente a busca dos trabalhadores por empresas que atuam com a remuneração por participação nos resultados. Segundo o autor, cerca de $63,3 \%$ dos colaboradores são atraídos por essa forma de remuneração. De acordo com Rodrigues, Neto e Filho (2014), o PPR atua como uma ferramenta de comprometimento e motivação aos colaboradores, elevando os índices de eficácia, possibilitando o cumprimento das metas estabelecidas.

Alguns pesquisadores enfatizam que o PPR quando aplicado e gerenciado de forma correta, atua como um instrumento que auxilia no comprometimento e na busca pelos resultados e alcance das metas por parte dos colaboradores (MOWDAY et al.,1982; BECKER; RUAS, 1997). Para os autores, as formas de participação nos resultados podem ser classificadas em dois grupos, um deles referente a participação nos lucros, e outro voltado para a participação dos resultados. Os programas de participação nos lucros são aqueles em que as distribuições são baseadas no lucro obtido pela organização em determinado período, estando diretamente ligado à lucratividade da empresa. Já a participação nos resultados, a concessão dos benefícios está atrelada aos resultados que são atingidos, não se limitando apenas aos lucros. Nesse sistema, o benefício pode ser dado pelo cumprimento de uma meta, pela qualidade alcançada nos produtos ou serviços, pela diminuição de acidentes ou de rotatividade, por exemplo. 
Esse estudo teve por propósito verificar se o PPR atua como fator de comprometimento, sob a ótica dos colaboradores da Cooperativa de Crédito Cresol Baser, delimitando os objetivos específicos da pesquisa em: analisar se o PPR atua como um fator de comprometimento dos colaboradores da Cooperativa de Crédito; verificar se o alcance das metas da Cooperativa de Crédito está atrelado ao PPR; averiguar se há outros fatores além do PPR que possam instigar o comprometimento dos colaboradores.

A organização estudada foi a Cooperativa Central de Crédito Rural que tem como denominação, Cooperativa de Crédito Cresol Baser, estabelecida na cidade de Francisco Beltrão - PR. Dentro do sistema financeiro nacional, a Cresol Baser atua como base prestadora de serviços. É na Central que estão alocadas as áreas, departamentos e setores que prestam serviços às cooperativas e seus cooperados e segue orientações do Banco Central do Brasil (INFOCOS, 2016).

\section{GESTÃO ESTRATÉGICA DE PESSOAS}

A relação da área de Recursos Humanos com a estratégia organizacional se deu a partir da década de 1980, tendo ênfase no planejamento de Recursos Humanos voltado ao alinhamento da gestão estratégica da organização. Esse alinhamento envolve a interação da força de trabalho com a questão social da organização. Dessa forma, é possível transmitir a filosofia organizacional a todo o contexto humano da instituição (ALBUQUERQUE, 1987; ULRICH, 1998; MARTíN; ROMERO; SÁNCHES, 2008).

Mascarenhas (2009) define a gestão estratégica de pessoas como qualquer mobilização, direcionamento, orientação, e administração de colaboradores ao articular uma estratégia organizacional envolvendo a área de Recursos Humanos e garantindo a todos que compõem a organização que tenham total entendimento 
sobre as estratégias para que todos os indivíduos que fazem parte da organização conduzam seus esforços ao objetivo central.

Por sua vez, Mathis e Jackson (2003) introduzem a gestão estratégica de pessoas sendo a capacidade de coordenar os recursos humanos através de políticas e ações que visem conquistar e assegurar vantagem competitiva, diferenciando a organização das demais. Nesse contexto, a principal fonte de competências para as organizações são as pessoas, por isso é importante que os gestores tracem metas que instigam os colaboradores a permanecerem na organização.

Dentro da ênfase organizacional, a gestão estratégica de pessoas atua como um elo entre o trabalhador e a organização, pois cabe aos responsáveis pela gestão de pessoas compreender as relações e interações dos indivíduos dentro do ambiente de trabalho. Essa compreensão permite elaborar reflexões sobre como o comportamento do indivíduo pode afetar o ambiente produtivo da organização (MARRAS, 2010).

Em seus estudos Fernandes e Berton (2012) afirmam que a gestão estratégica está ligada diretamente às pessoas que compõem a organização. Por meio do trabalho das pessoas, que a organização consegue enriquecer e alcançar seus objetivos. Assim, cabe aos gestores de RH desenvolver técnicas que mantenham sua força de trabalho motivada, competitiva e engajada aos objetivos organizacionais. Assim, a preocupação em torno da gestão estratégica de pessoas está voltada ao alcance dos objetivos organizacionais por meio de atividades que sejam realmente inovadoras para os indivíduos (MARRAS, 2010).

A gestão estratégia de pessoas está ligada ao comprometimento dos indivíduos, pois são realizados investimentos que fomentam a valorização dos empregados através da criação de táticas que promovem o empenho individual e coletivo dos empregados em alcançar os objetivos organizacionais. Outro ponto de destaque é a 
participação dos empregados no processo do planejamento estratégico, onde é dada abertura para que eles possam expor suas ideias (ALBUQUERQUE, 1999).

Em seus estudos, Genari e Macke (2018) mencionam que a permanência do indivíduo na organização está vinculada às práticas organizacionais desenvolvidas pela gestão estratégica de pessoas. Os autores comentam que em um cenário competitivo, é imprescindível que a organização efetue métodos de retenção de colaboradores, tais como: gestão do clima organizacional, sistemas de recompensas e reconhecimento, programas de treinamento, gestão de carreira e avaliação de desempenho.

\subsection{Salário e remuneração}

Para Franco (2012) o salário pode ser entendido como o valor monetário que é pago ao empregado pela prestação de seus serviços, conforme descrito no contrato de trabalho. Inicialmente as prestações de serviços não eram pagam com moeda, como são atualmente. A palavra salário vem do latim e significa "pagamento com sal". Comumente os pagamentos eram realizados com sal, pois ele era usado na conservação de alimentos; posteriormente passou-se a realizar a troca de mercadorias pelo trabalho exercido e somente mais tarde o trabalho passou a ser pago com moeda (RIBEIRO, 2006).

O salário é visto como um valor econômico que é pago pelo empregador pela prestação de um serviço realizado pelo empregado durante o período em que este fica acatando ordens do empregador em função do contrato de trabalho (MARTINS, 2008; DELGADO, 2009; NASCIMENTO, 2009).

Entretanto, para Motta (2009) altos salários nem sempre são sinônimos de contentamento para os colaboradores, pois, para que a satisfação dos colaboradores seja alcançada, é preciso, além de bons salários que haja boa comunicação e 
harmonia entre empregado e empregador. A insatisfação em relação ao salário é comumente gerada quando o colaborador não tem conhecimento dos impactos que suas ações trazem para a organização.

Por sua vez, a remuneração consiste no valor obtido da soma do salário recebida juntamente com outras bonificações, como horas extras, auxílios e outros benefícios estipulados no contrato de trabalho (FRANCO, 2012). Dutra e Hipólito (2012) conceituam o termo remuneração como a contrapartida financeira e/ou econômica pelo trabalhado realizado por um indivíduo. Ainda segundo os autores, a remuneração atua como uma forma de recompensa pelo trabalho prestado.

Na perspectiva de Carvalho et al. (2011) o intuito para que a organização desenvolva um programa de remuneração está voltado ao objetivo de projetar recompensas, as quais estão ligadas principalmente às questões motivacionais e de dinâmicas organizacionais. Para tanto, é necessário que tais programas estejam alinhados com a cultura, valores e com a arquitetura organizacional da instituição.

Dentro do cenário competitivo entre as organizações, a temática da remuneração vem sendo cada mais estudada e os gerentes de gestão de pessoas apostam em métodos de remuneração para atrair e reter bons profissionais. Havendo uma adequada política organizacional e estruturação nas formas de remuneração, a empresa consegue maior competitividade, alavancando sua funcionalidade e adquirindo melhores resultados (MOREIRA et al., 2016).

Detoni (2013), em suas pesquisas, buscou analisar os fatores que levam os indivíduos a procurarem uma organização para trabalhar, destaca que um fator de grande influência nesta decisão é a remuneração. Assim, destaca que para que a organização seja atraente no mercado e consiga reter melhores profissionais é necessário que ela tenha um bom nível remuneratório, se comparada com demais organizações do mesmo segmento. 
A questão da remuneração está bastante ligada à questão motivacional por parte dos colaboradores. Os estudos de Mota (2013) sobre motivação, liderança e a importância da remuneração nesse processo, indicam que as recompensas financeiras são um elemento fundamental para a motivação dentro das organizações. A recompensa é um fator chave para que a organização conduza e motive seus colaboradores a alcançarem as metas e objetivos propostos.

\subsubsection{Remuneração Variável}

Uma, dentre várias, práticas adotas pelas organizações para conseguir melhores resultados e fazer com que os colaboradores atendam aos objetivos, está ligada às formas de remuneração variável. Isso se dá ao fato de as organizações estarem investindo cada vez mais no capital humano, com ênfase para as habilidades, competências e para o comprometimento de seus colaboradores (FAVARIM, 2011).

A remuneração variável, segundo Pontes (1995) permite remunerar os colaboradores de uma forma que parte de seus salários é fixa e outra parte não, sendo um acordo entre a empresa e os colaboradores. Na determinação do salário variável, é levado em consideração as questões do desempenho da empresa, do colaborador e de sua equipe de trabalho. Sendo assim, a remuneração variável faz com que o colaborador consiga atingir seus objetivos por meio das conquistas das metas da instituição.

Coopers e Lybrand (1996), complementam afirmando que as organizações passam a adotar um sistema de remuneração variável para estabelecer uma recompensa aos colaboradores pela dedicação que é colocada ao buscarem o alcance das metas estabelecidas pela organização. Dessa forma, conseguem motivar os colaboradores a buscar aperfeiçoamento profissional, mesclando os objetivos da instituição com os objetivos dos colaboradores. 
Ao estudar a relação da motivação com o trabalho, Tamayo e Paschoal (2003) destacam a forte interação entre os objetivos organizacionais com os interesses pessoais dos colaboradores, não obstante, por parte da organização existem as demandadas e exigências e para o colaborador cabe exercer as atividades designadas pela organização. Ao realizar as atividades demandadas, o colaborador não tem como objetivo gerar lucros a organização, mas sim satisfazer suas necessidades a fim de alcançar seus objetivos e expectativas por meio do trabalho. O colaborador entrega ao trabalho sua capacidade, esforço, conhecimento e comprometimento em troca de recompensas que possam servir de base para alcançar seus objetivos individuais.

A remuneração variável busca estabelecer uma relação entre a remuneração e os resultados esperados. Esse vínculo se dá por meio da variação dos valores que são pagos aos colaboradores, ou seja, quanto maior o resultado, maior será o ganho, elevando assim a motivação por parte dos colaboradores, pois esses se sentem como parte da organização (GARRIDO, 1999). Neste sentido, a seguir será apresentado o programa de participação nos resultados, foco deste estudo.

\subsection{Programa de participação nos resultados (PPR)}

Os primeiros programas de participação dos colaboradores nos resultados ocorreram no final do século XVIII, no ano 1797, em uma fábrica de vidro na Pennsylvania, Estados Unidos. Inicialmente foi conduzida por integrantes do clero protestante. O clero acreditava que a participação nos lucros seria vista como uma compensação aos problemas sociais causados através do processo de industrialização (GILMAN, 1891).

Uma das primeiras iniciativas relacionada ao PPR na França foi implantada por Edmé-Jean Leclaire em 1843. Leclaire era dono de uma fábrica e, ao fim do ano, contabilizou seus lucros e distribuiu parte dele aos seus colaboradores (JOÃO, 1998). 
Oliveira e Superti (2006) enfatizam que a Igreja Católica juntamente com o Papa Leão XIII pregava o PPR como uma medida social. Ainda segundo os autores, o PPR passou a ser mais presente nas empresas a partir da década de 1950, por meio das influências das organizações japonesas que utilizavam o programa como uma alternativa moderna para motivar as relações produtivas nas empresas.

Na França, desde os anos 50 o governo vem estimulando a implementação do PPR. No Reino Unido, a partir de 1978 o PPR teve crescimento devido aos incentivos do governo que criaram meios para promover a adesão ao programa. Nas empresas em que a política foi adotada, constatou-se um maior comprometimento por parte dos colaboradores. No Japão, uma entre quatro empresas utilizam o programa, e dentre essas, a política estava presente, em sua maioria, em organizações de pequeno porte (CORRÊA; LIMA, 2006).

Os autores citam em seu artigo o relatório da Comissão de Comunidades Europeias, que avaliou, no período de 1991 a 1996, o desempenho do PPR adotado pelos países membros da comissão. De acordo com o relatório, desta comissão, na grande maioria dos casos, o aumento da produtividade nas empresas esteve atrelado à adoção do programa.

Corrêa e Lima (2006) apontam em seus estudos que países como Japão, Estados Unidos, Inglaterra, Alemanha e França passaram a adotar o PPR nas organizações por possuírem uma economia mais avançada, já que nesses países a política do programa atua como uma forma de incentivo que acaba movimentando a economia e gerando o pleno emprego.

As empresas passaram a adotar os programas da administração participativa como uma forma de estratégia, pois necessitavam de táticas que tivessem foco na satisfação de seus clientes e no aumento da produtividade. A implantação se deu 
devido à grande competitividade, revolução tecnológica, abertura de mercados e a globalização econômica (TUMA, 1999).

Em alguns países da América Latina como Chile, México, Peru e Venezuela, as experiências em programas de participação nos lucros são determinadas, em sua maioria, através de via legal, ou seja, há legislações que tratam sobre essa temática (LOBOS, 1990).

No Brasil, a temática da administração participativa está presente desde a década de 1940. Foi a partir das décadas de 1980 e 1990 que o tema passou a ser mais abrangente, devido à pressão exercida pelos sindicatos dos trabalhadores em incluir maior participação dos colaboradores em processos de decisão, tendo por intuito diminuir o sistema tradicional de administração (DEDECA, 1997).

Segundo Costa (1997) a chegada do PPR ao Brasil se deu através das organizações multinacionais a partir de 1980. Para as empresas brasileiras, a administração participativa atuou como uma forma de romper a estrutural organizacional vertical, pois esta aposta em uma estrutura mais verticalizada e mudando a estratégia de custo fixo elevado para uma estratégia de custos variáveis nas remunerações, mediante o PPR, passou a ser um atrativo para as organizações.

$\mathrm{Na}$ época, as organizações apostavam em meios de conseguir maior comprometimento e produtividade, para tanto, deveria apostar em novas alternativas, uma dessas alternativas tratava-se dos programas da administração participativa ou PPR, pois os colaboradores dedicavam-se de forma intensa para obter as metas da organização, fazendo-a mais competitiva no mercado (OLIVEIRA; SUPERTI, 2006).

Dentro deste contexto, o programa de participação nos lucros ou resultados passou a ser qualquer procedimento pelo qual o empregador paga ou facilita aos seus empregados a posse, sob determinadas regras de elegibilidade e condições 
econômicas, de determinadas somas correntes ou diferidas que são retiradas dos lucros da empresa (METZGER, 1975).

Segundo Chiavenato (1992) o PPR engloba uma participação pré-definida, em que parte dos resultados atingidos pela organização em determinado período, são distribuídos entre seus integrantes (colaboradores, gerentes, acionistas etc.). Esses resultados, tanto financeiros como contábeis devem estar concluídos e acessíveis.

Os programas de participação nos lucros ou resultados estão previstos tanto na Constituição Federal como na Consolidação das Leis Trabalhistas (CLT). Entretanto, somente no ano 2000, o PPR ganhou maior espaço através da promulgação da Lei Federal 10.101. De acordo com a Lei, toda empresa tem a possibilidade de implementar um programa de participação nos lucros ou resultados, com o intuito de recompensar os colaboradores pelos resultados atingidos. Para conceder essa bonificação, a empresa passa por um processo de implementação realizando uma negociação, onde o sindicato da categoria e o grupo de representantes dos trabalhadores participam (BRASIL, 2000).

Dessa forma, houve a regulamentação da participação dos colaboradores nos lucros e resultados da organização. A regulamentação da lei atua como um instrumento de integração entre o trabalhador e o capital, fomentando a produtividade. A lei também elimina encargos sobre os valores que são pagos pelo PPR, com isso a organização concede os benefícios com custos menores (OLIVEIRA; SUPERTI, 2006; MOTTA, 2009).

Embora todos os colaboradores sejam elegíveis, ou seja, possuem direito de participar do programa, cabe a organização estabelecer objetivos, indicadores e metas de desempenho para que os valores sejam pagos. Dessa forma, fatores como nível hierárquico, área de atuação e a relação do cumprimento das metas individuais 
ou coletivas podem implicar em recebimentos com valores diferentes para cada colaborador (BRASIL, 2000).

A ideia de implantar um PPR é de que a partir da remuneração extra ou da premiação recebida, o colaborador faça uma reflexão sobre os processos de trabalho dentro da empresa, levando-o a desenvolver a busca pelo sucesso contínuo da empresa que está inserido. Sendo assim, o colaborador se empenha em atingir as metas estabelecidas (PONTES, 1995).

Nesse sentido, Flannery et al. (1997), comenta que os programas de remuneração variável fazem com que as organizações comecem a compreender que a questão da remuneração precisa estar atrelada ao desempenho individual e ao desempenho da equipe, tendo uma visão mais voltada aos valores pessoais e organizacionais. Assim, as organizações conseguem perceber que seus ganhos estão ligados ao envolvimento e ao comprometimento da organização e do trabalhador.

Costa (1997) enfatiza que empresas que trabalham com programas de remuneração conseguem fazer com que seus colaboradores trabalhem mais, tornando-se mais competitivas. Portanto, a empresa consegue atrair profissionais mais instruídos para trabalhar, transformando o que antes era um custo em fatores controláveis e aumentando a motivação dos colaboradores.

Ao estudarem os efeitos da participação dos colaboradores no desempenho de empresas cooperativas da França, Defourney et al. (1985) obtiveram resultados positivos - entretanto pequenos, cerca de 5\% de aumento na produção em 1985 - na relação entre a produção e medidas de participação dos trabalhadores com a produtividade. Assim, os autores constataram que investindo em tecnologias de gestão, a participação dos colaboradores nos resultados servirá como uma ferramenta para aumentar a produtividade das empresas cooperativas. 
Algumas empresas, por estarem perdendo competividade e sendo afetadas pelos concorrentes passaram a adotar programas de participações econômicas. Jones e Pliskin (1988) ao realizar um levantamento empírico sobre o programa em países como Alemanha, Estados Unidos, França, Japão, Itália e Vietnã elencaram os principais efeitos da participação do trabalhador nos resultados econômicos nas organizações desses países.

Os autores consideram os programas de participação econômica como um elemento positivo que acaba aumentando a produtividade nas organizações. Entretanto, é preciso que a organização sabia gerir e aplicar de forma correta essa política, pois corre-se o risco de a organização não conseguir um resultado positivo. Na pior das hipóteses, as políticas de participação têm um efeito neutro e, em muitos casos, podem melhorar o desempenho. O resultado depende das características de aplicação de cada programa e de cada organização. A prova é de que, para o colaborador, os regimes de participação possuam impacto positivo.

Ben-ner e Jones (1995) ao analisarem o PPR em empresas americanas, constaram que os resultados podem ser tanto negativos como positivos. Os resultados serão positivos quando a organização permitir que o colaborador tenha participações monetária e decisórias; os resultados negativos são oriundos quando os funcionários não obtêm retornos significativos e quando não há participação decisória por parte dos funcionários.

Bassi (1995) ao analisar a questão da participação dos colaboradores nos lucros e resultados de empresas brasileiras, evidenciou que o tema é complexo e abrange questões políticas, de gestão e de legislação. O autor concluiu que o programa atua mais como uma forma de modernização para as empresas, e para que os colaboradores estejam engajados no programa é primordial que a empresa deixe claro como se dá o funcionamento do programa. Com base nos modelos teóricos, o autor concluiu que a participação nos lucros atua de forma favorável no componente 
motivacional dos colaboradores, ou seja, o programa pode ser usado para alçar melhorias de desempenho e da produtividade.

O PPR foi alvo de estudos voltados para acelerar a reestruturação financeira das empresas no Brasil. O programa é visto como um valioso instrumento para a gestão das organizações, pois pode atuar como um incentivo aos colaboradores, fazendo-os terem maior comprometimento com seu trabalho em períodos de reestruturação das empresas (MARINAKIS, 1997).

Becker (1998) ao estudar as experiências do PPR em uma empresa do Rio Grande do Sul, identificou inicialmente que o foco dos gestores em aderirem ao programa estava centrado em trazer benefícios ao trabalhador. Ao aprofundar as entrevistas, concluiu que, para a organização, a política de participação nos resultados dava mais ênfase na gestão da empresa do que nas vantagens para o trabalhador, pois, destacaram que a distribuição só ocorre quando há resultados financeiros.

Ao pesquisar sobre o programa de participação em uma indústria moveleira do Rio Grade do Sul, Costa (2000) pode concluir através da análise dos dados, que o PPR adotado pela organização obteve resultados positivos na influência do comprometimento organizacional dos colaboradores em estudo, pois observou que a partir da implantação do programa, a organização conseguiu atingir resultados positivos no decorrer dos anos. Com relação às influências do programa sobre o comprometimento dos trabalhadores, o autor constatou que os colaboradores acabaram sendo influenciados pelo programa a trabalharem em prol do objetivo da organização.

Medeiros e Heidemann (2000) estudaram sobre o PPR em um complexo industrial da WEG de Jaraguá do Sul - SC. Através das respostas dos participantes e das análises realizadas pelos pesquisadores, foi concluído que o programa não é um dos principais fatores motivacionais da empresa. Contudo, auxiliou na melhoria do 
clima organizacional, no desempenho, na produtividade e na qualidade do trabalho. $\mathrm{Na}$ organização em estudo, o programa não motivou os colaboradores, pois não atendeu por completo as expectativas destes, juntamente com o descontentamento das diretrizes do programa.

Ao analisar as semelhanças e diferenças entre o PPR em três empresas de processamento de fumo no Rio Grande do Sul, Alves (2002) constatou que o programa gerou vantagem de ordem econômica e social. Os gestores das três empresas afirmaram que os colaboradores se sentiram motivados e trabalhavam para alcançar melhores resultados, sendo mais participativos e contribuindo com sugestões e melhorias. Porém, a pesquisa revelou que nem todos os empregados estavam satisfeitos com o programa, pois o valor monetário que recebiam não compensava o esforço extra que realizavam. Em suma, o autor concluiu que o programa trouxe benefícios às empresas, mesmo havendo alguns pontos que precisariam ser ajustados.

Poutsma, Hendrickx e Huijgen (2003) avaliaram a visão geral do PPR nos resultados de diferentes países da União Europeia. Os países europeus possuem várias organizações que trabalham com essa política, entretanto atuam com nível baixo de participação entre organização e colaborador. Observou-se que os programas são mais aplicados em países da França e Reino Unido em organizações que possuem força de trabalho mais qualificada.

Em seus estudos em uma empresa de software Farzan et al. (2008) estudaram a questão do PPR onde os colaboradores eram premiados pelo número de conteúdo que incluíam no site. Os resultados quantitativos mostram que os funcionários que acataram o sistema de participação tiveram uma contribuição e aumento imediato após a sua inclusão. A partir do estudo identificou-se que os colaboradores estão motivados pelos pontos e níveis de status dentro do que o sistema proporcionou. Dessa forma, constatou-se que para alcançar o desejo dos colaboradores em receber 
algo em troca por suas contribuiç̧̃es, uma abordagem a ser utilizada são os mecanismos de recompensa por contribuição ou participação.

Seguindo a mesma linha de pesquisa, Brondani e Silva (2003) ao estudar o PPR em uma empresa, conseguiram identificar que boa parte dos colaboradores se sentiam motivados em trabalhar para alcançar as metas. Entretanto, boa parte dos participantes informaram que se sentem indiferentes em relação ao programa.

\subsection{Comprometimento organizacional}

O comprometimento organizacional segundo Porter, Steers e Mowday (1974) está relacionando com a crença dos colaboradores em acatar as metas e valores da organização, realizando as atividades com disposição e esforço em favor da instituição, realizando as tarefas segundo as decisões da empresa, ou seja, torna-se um conjunto de envolvimentos e ações do funcionário com a empresa. O comprometimento organizacional está atrelado aos valores e ao comportamento dos colaboradores, onde seu comprometimento acaba resultando em melhores níveis de produtividade, desempenho e pontualidade (SCHWARTZ, 1992; BASTOS, 1994; REGO; SOUTO, 2002).

Dubrin (2003) conceitua o comprometimento organizacional como sendo o estudo do comportamento da interação humana no local de trabalho. Para Robbins (2005) o comprometimento organizacional está atrelado aos estudos que as pessoas fazem na empresa e de como seus modos interferem no desempenho da organização. Barros (2007) discorre sobre o comprometimento organizacional como um meio que a organização utiliza para alavancar negócios, tornando-o indispensável para que se tenha um ambiente mais agradável e com maiores resultados. 
Quanto maior o comprometimento dos colaboradores, maior será o alcance dos objetivos organizacionais. Quando a organização consegue maior comprometimento de seus colaboradores, esses conseguem satisfazer as necessidades organizacionais com maior êxito, alavancando os objetivos e metas da empresa (VEIGA et al., 2019).

Nesse contexto, Meyer et al. (2002) aponta que os maiores níveis de comprometimento organizacional foram encontrados em colaboradores que possuem maior idade, maior período de permanência na organização, remuneração mais elevada e um cargo mais elevado. Entretanto, são poucos os estudos que buscam verificar se os programas de participação nos resultados atuam como um fator de comprometimento organizacional.

A partir de suas pesquisas, Zonatto, Silva e Gonçalves (2018) verificaram que se a gerência da organização não estiver comprometida o suficiente, os colaboradores que se encontram em cargos inferiores podem apresentar um comprometimento abaixo do esperado. Sendo assim, quanto maior o comprometimento da gerência da empresa, mais seus colaboradores estarão comprometidos com a organização. Sendo assim, cabe a gerência, juntamente com o departamento de Recursos Humanos implantar estratégias de comprometimento que atinjam a todos os cargos da empresa.

Dentro da abordagem do comprometimento organizacional, tem-se o conceito de Meyer e Allen (2001), o qual corresponde aos vínculos que o colaborador possuiu com a organização e como esses vínculos se desenvolvem no ambiente de trabalho, sendo eles: afetivo/atitudinal, instrumental/calculativo e normativo.

Com relação ao termo afetivo/atitudinal, ele trata a questão da internalização do vínculo entre o colaborador e os objetivos, valores, crenças e metas da organização em que está inserido. O colaborador que possui uma postura voltado ao 
afetivo/atitudinal atua de forma mais ativa dentro da organização, demonstrando maior esforço, orgulho e desejo de pertencer a empresa. Com isso, a organização consegue maior comprometimento e lealdade por parte do colaborador (BORGESANDRADE; ABBAD; MOURAO, 2007).

No que diz respeito ao enfoque instrumental/calculativo, Becker (1960) trata deste como estando relacionado com as trocas entre a organização e o indivíduo, ou seja, o colaborador continua na organização devido aos custos e benefícios de seu desligamento (saída). Bandeira, Marques e Veiga (2000) tratam desse enfoque relacionando o reconhecimento do colaborador por parte da empresa, ou seja, o colaborador permanecerá na organização enquanto houver retornos derivados de seu empenho. Se seu empenho for maior do que o retorno esperado, certamente abandonará a empresa.

Já, o enfoque normativo é baseado na convicção de que o empregado se compromete em razão das pressões normativas e regras da organização. O colaborador entende as regras e normas da instituição como uma obrigação sendo fundamental seguir as normas para alcançar os objetivos e metas da organização e, desta forma, satisfazem suas necessidades. Com isso, o colaborador segue as normas da organização, pois recebe benefícios que o instiga a praticar as normas e culturas da organização (WIENER, 1982).

\section{PROCEDIMENTO METODOLÓGICO}

A pesquisa utiliza-se da abordagem de natureza quali-quanti, que segundo Telles Junior (2019) é baseada na junção da abordagem quantitativa com a qualitativa, ou seja, baseiam-se nos resultados encontrados nas duas abordagens.

Segundo Oliveira (1997) a abordagem quantitativa caracteriza-se como o método que quantifica as opiniões, formas e as informações coletadas, bem como a 
utilização de meios estatísticos que são utilizados para mensurar os dados. A abordagem quantitativa tem por sua principal característica a quantificação dos dados e tem foco na objetividade, onde os resultados obtidos são tomados como base para representar um retrato de toda a população do público alvo da pesquisa. Nesta abordagem, acredita-se que a realidade só pode ser analisada a partir de dados que são coletados com instrumentos neutros e padronizados (FONSECA, 2002).

A pesquisa qualitativa é baseada na percepção e compreendimento humano sobre determinado tema, representando visões e perspectivas dos participantes do estudo, explicando os acontecimentos e produzindo revelações, ou seja, trata da importância das perguntas do pesquisador e das respostas do pesquisado para a produção do conhecimento. A pesquisa qualitativa permite uma interpretação mais dinâmica, pois considera que os fatos não podem ser analisados isoladamente. Permite também ao autor aprofundar em seus temas de pesquisa, bem como uma maior seleção de temas (GIL, 2008; REY, 2005; STAKE, 2011; YIN, 2016).

O método de pesquisa utilizado consiste na pesquisa de campo por levantamento ou survey e para responder aos objetivos destaca-se a pesquisa descritiva e exploratória. Para Gressler (2004) o objetivo da pesquisa descritiva é elencar quais os fatos e características que estão presentes em determinada área de interesse ou população. Esse método é utilizado quando o pesquisador quer descrever algum fenômeno existente, situações e eventos a fim de identificar os problemas e justificar os resultados. A pesquisa descritiva não fica restrita somente à tabulação dos dados, pois o elemento interpretativo necessita de mensurações, comparações, avaliações e interpretações. Segundo Rampazzo (2005) a pesquisa descritiva analisa e correlaciona as variáveis, estudando-as sem a interferência do pesquisador. Esse método busca encontrar a frequência com que um fenômeno ocorre e sua conexão com outros e sua natureza. 
Já o método exploratório busca atingir maior familiaridade com o tema estudado a fim de construir hipóteses ou torná-lo mais explícito, buscando maiores informações sobre o tema, como suas causas e consequências, a fim de deixa-lo mais claro. Proporciona ao pesquisador maiores informações sobre o tema e auxilia a delimitar e atingir seu objetivo (RICHARDSON, 1989; GIL, 2008; CIRIBELLI, 2003).

Para fins de coleta de dados com abordagem quantitativa utilizou-se da identificação da população e amostra. Landim (2003) conceitua população como o conjunto de componentes que possuem as características que serão objeto do estudo. Para tanto, a população referente à pesquisa foram os colaboradores da Cooperativa de Crédito Cresol Baser, localizada na cidade de Francisco Beltrão-PR, totalizando 210 colaboradores. Ainda, segundo o mesmo autor, a amostra seria o subconjunto de elementos da população, a qual é submetida a um processo de amostragem.

Para delimitar a amostragem, utilizou-se o cálculo de amostra de Barbeta (1984). Utilizando a população de 120 colaboradores, com nível de confiança de 95\% e com um erro amostral de 4\% delimita-se a amostra em 101 colaboradores. Para tanto, foi utilizada a amostragem por conveniência, que segundo Silva (2011) é a amostra em que o pesquisador escolhe os entrevistados, conforme a disponibilidade dos participantes.

$\mathrm{Na}$ abordagem qualitativa, o sujeito social foi uma das Gestoras de $\mathrm{RH}$ da instituição em estudo. A entrevista teve foco na Gestora de $\mathrm{RH}$, pois ela atua diretamente com os sistemas de remuneração e estuda e aplica políticas para alcançar maiores metas, motivação e comprometimento por parte dos colaboradores. Sendo assim, a profissional possui conhecimento sobre o tema em questão.

No que diz respeito à abordagem quantitativa o instrumento de coleta de dados utilizado foi um questionário com questões fechadas, em sua maioria. Lopes (2006) define o questionário como um instrumento de coleta de dados formado por 
perguntas ordenadas, bem estruturadas e de acordo com o assunto abordado, devendo ser respondido sem a interferência do pesquisador. O questionário é usado para dar apoio ao pesquisador na sua coleta de dados, por isso deve ser bem formulado, claro e específico.

O questionário utilizado para o levantamento dos dados foi o questionário adaptado do modelo proposto por Mowday et al. (1982). Ao elaborar o questionário, o autor teve como objetivo verificar quais seriam as influências do PPR no comprometimento organizacional dos colaboradores de determinada organização.

O questionário abrange questões dispostas em três dimensões dentro da conceituação de comprometimento defendidas por Mowday et al. (1982), sendo: esforço, identificação e lealdade, os quais estão relacionadas com o comprometimento e motivação em relação ao programa de participação nos resultados. No questionário, os itens 1 , 8, 13, 14 e 15 remetem ao fator esforço (instrumental/calculativo); ao fator da identificação (normativo), aplicam-se os itens 2 , 5, 6, 10 e 12; os itens 3, 4, 7, 9 e 11, referem-se ao fator lealdade (afetivo/atitudinal). Ao final duas questões abertas foram incluídas para que os colaboradores pudessem discorrer livremente.

A escala utilizada compreende a escala tipo Likert de 5 pontos. Essa escala tem por intuito mensurar a intensidade das atitudes e opiniões de forma que seja precisa e possível de mensurar, pois os respondentes podem indicar o grau de concordância ou discordância em cada uma das questões apresentadas. Os pontos vão de "discordo totalmente" a "concordo totalmente", apresentando pontos extremos, intermediários e de quebra (GIL, 2008; ROSSI; SLONGO, 1998; MALHOTRA, 2012).

Para apurar a confiabilidade do questionário utilizado para a coleta dos dados, o autor do questionário original Mowday et al. (1982) realizou os testes de consistência interna Alfa de Cronbach para verificar a consistência e confiabilidade do 
seu instrumento. Em seus testes, o autor atingiu um coeficiente Alfa de Cronbach de 0,82 a 0,93. Pasquali (1997) aponta que quanto mais próximo a 1 for o coeficiente Alfa de Cronbach maior é confiabilidade do instrumento utilizado e menores são as chances de ocorrer erros na realização de testes e análises.

A entrevista semiestruturada foi utilizada para a abordagem qualitativa. Triviños (1987) descreve a entrevista semiestruturada como forma básica de questionamento que são apoiados nas bases teóricas que se relacionam com o tema a ser pesquisado. A entrevista consiste em obter informações por meio de uma conversa com questionamentos já direcionados a determinado assunto. Manzini (1991) complementa que as entrevistas semiestruturadas atuam como um roteiro, possibilitando ao entrevistador obter as respostas de forma mais livre.

O roteiro que compõe a entrevista com uma das Gestoras de RH foi elaborado e adaptado com base em Becker (1998), Bassi (1995) e Alves (2002). Tomando os autores como base, foram adaptadas algumas questões, tais como: "Quais os desafios e resultados da implantação do PPR na Cooperativa de Crédito Cresol Baser?"; "O que motivou a Cooperativa de Crédito Cresol Baser a adotar este Plano?"; "A organização percebe alguma evidência que caracterize mudança de comportamento do funcionário após a utilização do plano?" "O alcance das metas e objetivos da Cooperativa de Crédito Cresol Baser tem alguma alteração após a adoção do plano?"; "Que resultado(s) a Cooperativa de Crédito Cresol Baser tem obtido, nos últimos anos, com o emprego do PPR da empresa?"; "Qual é a sua opinião quanto ao comprometimento dos empregados com o PPR da Cooperativa de Crédito Cresol Baser?".

Segundo Carvalho (1989) a coleta de dados é a parte em que a pesquisa se inicia. É a partir dos dados coletados que será possível atingir a resposta do problema de pesquisa. As coletas dos dados foram de ordem primária, na qual Gustin e Dias (2006) os caracterizam como sendo os dados que são coletados e tabulados direto 
pelo pesquisador, sem ter origem de outras fontes. Comumente, as fontes primárias dão uma originalidade aos resultados do pesquisador, por serem coletadas diretamente entre o pesquisador e o informante.

Quanto aos procedimentos de tratamento dos dados quantitativos foram utilizadas as análises descritivas, assimetria e curtose, correlação $r$ de Pearson e análise de Regressão Múltipla. A análise dos dados coletados na entrevista e nas duas questões abertas do questionário foi realizada a análise temática. Os dados estatísticos, na etapa quantitativa, foram tratados com os softwares Microsoft@ Office Excel ${ }^{\circledR}$ e IBM $®$ SPSS $®$ Statistics - Statistical Package for the Social Sciences, versão 18.

$\mathrm{Na}$ análise das variáveis qualitativas, utilizou-se a análise temática. Segundo Rampazzo (2005) é a base para um resumo ou síntese sobre determinando assunto, tendo por objetivo apresentar a sequência lógica das ideias expostas, permitindo elaborar um roteiro de leitura. Desidério (2010) discorre sobre a análise temática como uma ferramenta que se fundamenta no tema estudado e busca descobrir os núcleos do sentido das questões estudadas.

Ainda segundo o autor, a análise temática organiza-se em três etapas: a préanálise que é a fase da organização e sistematização das ideias iniciais; a exploração do material que é a etapa mais longa, e consiste em codificar, enumerar e comparar os estudos para a identificação do que de fato é relevante; por fim o tratamento e interpretação dos resultados; o tratamento dos resultados e interpretações consiste em tratar os dados com objetivo de torna-los válidos. Sendo assim, o pesquisador poderá levantar interpretações em relação ao caso estudado, podendo desencadear novas descobertas e interpretações sobre o assunto estudado.

Dos 95 questionários válidos, havia duas questões abertas e opcionais para que os respondentes pudessem discorrer, sendo elas: questão 1 - Quais as influências do PPR no seu comprometimento com a Cooperativa de Crédito Cresol Baser?; e a 
questão 2 - Tem algo que você gostaria de destacar que contribui para o comprometimento com a Cooperativa de Crédito Cresol Baser? Cada colaborador deu a sua resposta, após recolher os questionários transcreveu-se todas as respostas no Excel. A próxima etapa foi a organização dos dados, que foi realizada da seguinte forma, criou-se um quadro para fazer a súmula das respostas. A súmula das respostas são palavras ou trechos mais objetivos que corresponde às respostas das perguntas que foram realizadas. Nesta etapa buscou-se ser o mais verdadeiro e honesto possível na interpretação das respostas para que a súmula realmente expressa-se o que o respondente quis dizer, buscou-se não ocultar palavras pois estas poderiam dar outro sentido ou significado a resposta.

Com a súmula a interpretação das respostas ficou mais clara e objetiva, assim, podem ser feitas análises e comparações entre elas, lembrando que se buscou não fazer juízo de valor e nem tirar conclusões, apenas dar clareza as respostas.

\section{APRESENTAÇÃO E ANÁLISE DOS RESULTADOS}

A seguir apresenta-se os resultados da pesquisa com relação às avaliações dos colaboradores da Cooperativa de Crédito Cresol Baser em relação ao PPR como fator de comprometimento organizacional. A coleta de dados foi realizada no mês de agosto de 2019 com 101 colaboradores. Durante a tabulação dos dados, foram descartados seis questionários por estar incompleto, o que resultou em 95 respondentes válidos. Será apresentada também a entrevista com uma gestora do departamento de Recursos Humanos.

Pode-se caracterizar os colaboradores participantes da pesquisa, preponderantemente sendo do sexo feminino, com idades entre 21 a 31 anos, tendo em sua grande maioria até 6 anos de trabalho na instituição em estudo, atuando predominantemente nos setores da Carteira de Credito, Gerência Jurídica, Supervisão e Controle, Seguros, Comercial, Gerencia de Relacionamento e T.I., com bom grau de 
escolaridade, pois o maior número dos respondentes possuiu graduação e pósgraduação, contando com salários que variam de 3 a 6 salários mínimos.

\subsection{Análise quantitativa dos dados}

A seguir serão apresentadas as variáveis referentes ao PPR e o comprometimento organizacional na percepção dos colaboradores. A Tabela 01 apresenta a análise descritiva.

Tabela 1 - Análise descritiva das variáveis

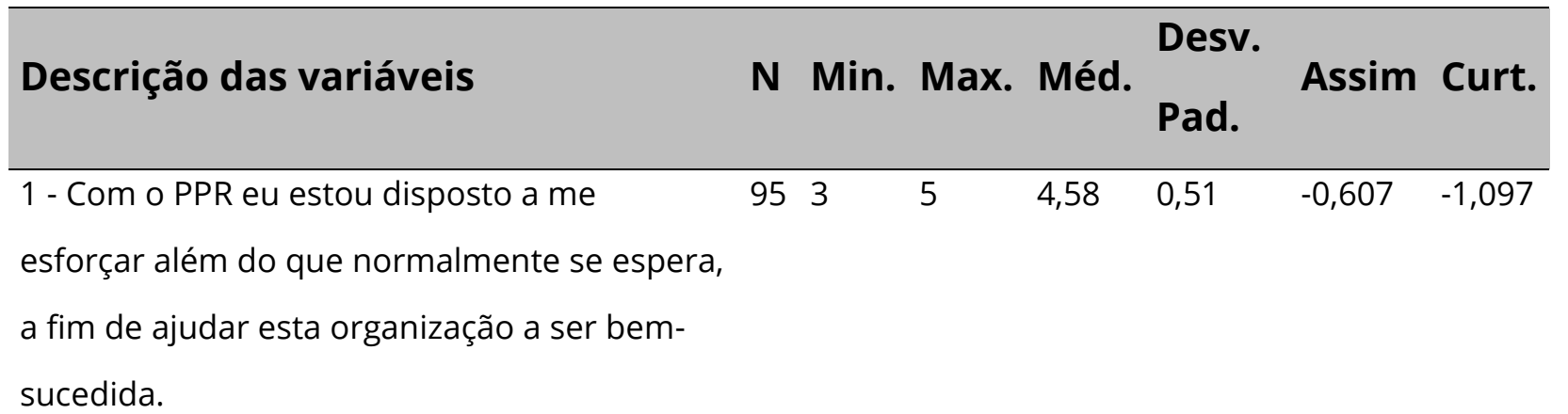

2 - O PPR fez com que eu fale desta

$\begin{array}{lllllll}95 & 1 & 5 & 4,34 & 0,83 & -1,741 & 4,222\end{array}$

organização para meus amigos, como uma

grande organização para trabalhar.

3 - O PPR me faz sentir lealdade com relação a $\begin{array}{lllllll}95 & 1 & 5 & 4,13 & 0,94 & -0,827 & 0,060\end{array}$ esta organização.

4 - O PPR faz com que eu aceite qualquer $\quad \begin{array}{lllllll}9 & 1 & 5 & 3,38 & 1,12 & -0,270 & -0,664\end{array}$

tarefa de trabalho a fim de ficar trabalhando

para esta organização

5 - A partir do PPR eu noto que meus valores $95 \begin{array}{lllllll}1, & 5 & 3,89 & 1,01 & -0,877 & 0,583\end{array}$

e os valores da organização estão muito mais

parecidos.

6 - Com o PPR eu tenho orgulho de contar $\quad 95$ 1, $\quad \begin{array}{llllll}4,10 & 096 & -0,948 & 0,333\end{array}$

para os outros que trabalho nesta

organização.

7 - Acredito que após o PPR eu não

$\begin{array}{lllllll}95 & 1 & 5 & 3,34 & 1,02 & -0,027 & -0,739\end{array}$

trabalharia para outra organização, mesmo 
Descrição das variáveis

que o tipo de trabalho fosse parecido.

8 - Com o PPR essa organização realmente

me motiva a progredir no desempenho de

meu trabalho

9 - A partir do PPR seria preciso uma grande

mudança na minha atual situação ou da

minha vida como um todo, para me fazer sair

desta organização.

10 - Após o PPR eu estou extremamente

satisfeito de ter escolhido esta organização

para trabalhar, comparando com outras

organizações que avaliei na época de

contratação

11 - Com o PPR noto que posso progredir

muito mais, por isso, existem muitas razões

para me manter nesta organização para

sempre.

12 - O PPR faz com que eu, frequentemente,

concorde com as políticas desta organização

com relação a assuntos importantes

relacionados ao meu trabalho.

13 - O PPR realmente faz com que eu me

952

importe com o destino desta organização.

14 - A partir do PPR para mim essa é a melho

organização para se trabalhar.

15 - O PPR me faz perceber que minha

95

decisão em trabalhar para esta empresa foi

um acerto definitivo de minha parte.

16 - Atual estado de comprometimento para

953

com esta empresa.
N Min. Max. Méd.

\section{Desv.}

Pad.

Assim Curt.

$\begin{array}{lllllll}95 & 2 & 5 & 4,37 & 0,74 & -1,064 & 0,725\end{array}$

$\begin{array}{lllllll}95 & 1 & 5 & 3,86 & 1,01 & -0,870 & 0,279\end{array}$

$\begin{array}{lllllll}95 & 1 & 5 & 4,11 & 0,83 & -0,892 & 1,075\end{array}$

$\begin{array}{lllllll}95 & 2 & 5 & 3,94 & 0,90 & -0,779 & 0,043\end{array}$

$\begin{array}{lllllll}95 & 1 & 5 & 3,65 & 0,97 & -0,581 & -0,077\end{array}$

Fonte: Dados da pesquisa, 2019.

RGC, Santa Maria, v. 8, n.15, Jan./Jun., 2021. 
Primeiramente procedeu-se a análise de médias e desvio padrão e em seguida a análise de assimetria e curtose. Para Schwaab e Pinto (2007, p. 30) a média refere-se a “uma soma ponderada de vários números que aparecerem no conjunto original de dados. A ponderação utilizada é a frequência com que o número aparece no conjunto."

Quanto à média das questões, as questões que apresentaram maiores médias foram as questões: 1 Com o PPR eu estou disposto a me esforçar além do que normalmente se espera, a fim de ajudar esta organização a ser bem-sucedida; 16 Atual estado de comprometimento com essa empresa; e 3 - O PPR me faz sentir lealdade com relação a esta organização. Tendo em consideração as questões que obtiveram as menores médias, pode-se citar as questões: 7 - Acredito que após o PPR eu não trabalharia para outra organização, mesmo que o tipo de trabalho fosse parecido; 4 - O PPR faz com que eu aceite qualquer tarefa de trabalho a fim de ficar trabalhando para esta organização; e 12 - O PPR faz com que eu, frequentemente, concorde com as políticas desta organização com relação a assuntos importantes relacionados ao meu trabalho.

O desvio padrão identifica o grau de dispersão ou variabilidade de um conjunto de valores em relação a sua média, ou seja, quanto mais próximo a zero o valor do desvio padrão, mas próximo da média essa variável se encontra (CORREIA NETO, 2007). Se tratando do desvio padrão, as questões que obtiveram os menores desvios são as questões: 1 - O PPR me faz sentir lealdade com relação a esta organização; 16 Atual estado de comprometimento para com esta empresa; e 10 - Após o PPR eu estou extremamente satisfeito de ter escolhido esta organização para trabalhar, comparando com outras organizações que avaliei na época de contratação. Já as seguintes questões obtiveram maiores resultados de desvio padrão, sendo as questões: 4 - O PPR faz com que eu aceite qualquer tarefa de trabalho a fim de ficar trabalhando para esta organização; 7 - Acredito que após o PPR eu não trabalharia para outra organização, mesmo que o tipo de trabalho fosse parecido; e 9 - A partir 
do PPR seria preciso uma grande mudança na minha atual situação ou da minha vida como um todo, para me fazer sair desta organização.

Observando as análises de média e desvio padrão, há questões que foram citadas na relação de média e na relação do desvio padrão. Isso significa que há relação nas respostas dos respondentes, pois as duas questões que obtiveram maior média, também obtiveram menor desvio padrão, bem como as duas questões que apresentaram menor média obtiveram também maior desvio padrão, demonstrando que a maioria dos respondentes possuem uma opinião equivalente em relação a estas questões.

Das análises das médias e do desvio padrão, as questões que não se repetiram nas duas análises (média e desvio padrão), tomando como base os respondentes da pesquisa, percebeu-se que não há uma relação direta entre a maior média e menor desvio padrão e menor média com o maior desvio padrão. Isso demonstra que há uma maior dispersão das respostas.

Conforme consta na literatura a análise de assimetria segundo Hair Jr. et al. (2005) indica se a distribuição é substancialmente assimétrica. Para isso, é preciso que os resultados dos valores de assimetria apresentem indicadores maiores do que +1 ou menores do - 1. Já na curtose, de acordo com Hair Jr. et al. (2005, p. 274), "Uma curva é muito aguda quando a curtose excede +3 e é muito achatada quando ela fica abaixo de -3."

Após a análise da Tabela 1, três questões foram eliminadas, pois não atenderam aos critérios estabelecidos pela literatura nas análises de assimetria e curtose e iriam prejudicar as análises da pesquisa. As questões eliminadas foram as seguintes questões: 2 - O PPR fez com que eu fale desta organização para meus amigos, como uma grande organização para trabalhar; 8 - Com o PPR essa organização realmente me motiva a progredir no desempenho de meu trabalho; e 
questão 15 - O PPR me faz perceber que minha decisão em trabalhar para esta empresa foi um acerto definitivo de minha parte.

Os resultados da pesquisa foram agrupados com base na literatura sendo que os autores tomados como base para o instrumento de coleta de dados determinam que as variáveis sejam agrupadas em três fatores, e estas variáveis agrupadas estão apresentadas na Tabela 2, a seguir, juntamente com a média das variáveis de cada fator. Dentre os fatores elencados, o fator instrumental calculativo apresentou maior média, seguido do normativo e por último do afetivo.

Tabela 2 - Relação das análises de média

\begin{tabular}{l|l|c|c}
\hline Comprometimento & \multicolumn{1}{|c}{ Questão } & Média \\
\hline Intrumental/ & $\begin{array}{l}1 \text { - Com o PPR eu estou disposto a me esforçar } \\
\text { além do que normalmente se espera, a fim de } \\
\text { ajudar esta organização a ser bem sucedida. } \\
13 \text { - O PPR realmente faz com que eu me importe } \\
\text { com o destino desta organização. } \\
14 \text { - A partir do PPR para mim essa é a melhor } \\
\text { organização para se trabalhar. }\end{array}$ & 95,19 \\
\hline Normativo & $\begin{array}{l}\text { 5- A partir do PPR eu noto que meus valores e os } \\
\text { valores da organização estão muito mais parecidos. } \\
\text { 6- Com o PPR eu tenho orgulho de contar para os } \\
\text { outros que trabalho nesta organização. } \\
10 \text { - Após o PPR eu estou extremamente satisfeito } \\
\text { de ter escolhido esta organização para trabalhar, } \\
\text { comparando com outras organizações que avaliei } \\
\text { na época de contratação } \\
12 \text { - O PPR faz com que eu, frequentemente, } \\
\text { concorde com as políticas desta organização com } \\
\text { relação a assuntos importantes relacionados ao } \\
\text { meu trabalho. }\end{array}$ & 3,94 \\
\hline
\end{tabular}




\begin{tabular}{|c|c|c|c|}
\hline Afetivo/Atitudinal & $\begin{array}{l}3 \text { - O PPR me faz sentir lealdade com relação a esta } \\
\text { organização. } \\
4 \text { - O PPR faz com que eu aceite qualquer tarefa de } \\
\text { trabalho a fim de ficar trabalhando para esta } \\
\text { organização } \\
7 \text { - Acredito que após o PPR eu não trabalharia para } \\
\text { outra organização, mesmo que o tipo de trabalho } \\
\text { fosse parecido. } \\
9 \text { - A partir do PPR seria preciso uma grande } \\
\text { mudança na minha atual situação ou da minha vida } \\
\text { como um todo, para me fazer sair desta } \\
\text { organização. } \\
11 \text { - Com o PPR noto que posso progredir muito } \\
\text { mais, por isso, existem muitas razões para me } \\
\text { manter nesta organização para sempre. }\end{array}$ & 95 & 3,74 \\
\hline Comprometimento & $\begin{array}{l}16 \text { - Atual estado de comprometimento para com } \\
\text { esta empresa }\end{array}$ & 95 & 4,59 \\
\hline
\end{tabular}

Fonte: Dados da pesquisa, 2019.

Analisando os resultados das médias (escala de 1 a 5) voltados aos 3 tipos de comprometimento, observou-se que a maior média foi o instrumental/calculativo com valor de 4,19, por segundo o normativo com média de 3,94 e o afetivo/atitudinal com a menor média, sendo 3,74. Analisando a maior média, pode-se constatar que os colaboradores da Cooperativa de Crédito Cresol Baser possuem um grau de comprometimento ligado ao Instrumental/Calculativo, ou seja, o comprometimento se dá pelo que serão recompensados pelo esforço (BANDEIRA; MARQUES; VEIGA, 2000). 
4.1.1 Testes para análise de regressão

Após análise descritiva, para completar a descrição referente ao PPR como um fator de comprometimento procedeu-se uma série de análises para verificar a possibilidade de realizar a análise de regressão. Primeiramente foi realizada a análise de correlação $r$ Pearson, apresentada na Tabela 3.

Tabela 3 - Correlação $r$ de Pearson

\begin{tabular}{|c|c|c|c|c|c|}
\hline & & $\begin{array}{c}\text { Instrume } \\
\text { ntal/Calc } \\
\text { ulativo }\end{array}$ & $\begin{array}{c}\text { Normat } \\
\text { ivo }\end{array}$ & $\begin{array}{l}\text { Afetivo/ } \\
\text { Atitudin } \\
\text { al }\end{array}$ & $\begin{array}{c}\text { Comprometi } \\
\text { mento } \\
\text { Organizacion } \\
\text { al }\end{array}$ \\
\hline $\begin{array}{l}\text { Instrumental/ } \\
\text { Calculativo }\end{array}$ & $\begin{array}{l}\text { Pearson Correlation } \\
\text { Sig. (2-tailed) } \\
\mathrm{N}\end{array}$ & $\begin{array}{r}1 \\
95\end{array}$ & & & \\
\hline Normativo & $\begin{array}{l}\text { Pearson Correlation } \\
\text { Sig. (2-tailed) } \\
\mathrm{N}\end{array}$ & $\begin{array}{r}0,797 \\
, 000 \\
95\end{array}$ & $\begin{array}{r}1 \\
95\end{array}$ & & \\
\hline $\begin{array}{l}\text { Afetivo/ } \\
\text { Atitudinal }\end{array}$ & $\begin{array}{l}\text { Pearson Correlation } \\
\text { Sig. (2-tailed) } \\
\mathrm{N}\end{array}$ & $\begin{array}{r}0,709 \\
, 000 \\
95\end{array}$ & $\begin{array}{r}0,818 \\
, 000 \\
95\end{array}$ & $\begin{array}{r}1 \\
95\end{array}$ & \\
\hline $\begin{array}{l}\text { Comprometi } \\
\text { mento }\end{array}$ & $\begin{array}{l}\text { Pearson Correlation } \\
\text { Sig. (2-tailed) }\end{array}$ & $\begin{array}{r}0,428 \\
, 000\end{array}$ & $\begin{array}{r}0,371 \\
, 000\end{array}$ & $\begin{array}{r}0,424 \\
, 000\end{array}$ & 1 \\
\hline $\begin{array}{l}\text { Organizacion } \\
\text { al }\end{array}$ & $\mathrm{N}$ & 95 & 95 & 95 & 95 \\
\hline
\end{tabular}

Fonte: Dados da pesquisa, 2019.

Segundo a literatura, para que haja correlação é necessário que seja significativo $($ Sig<0,05). Nesse sentido, Dancey e Reidy (2005) conceitua como uma medida de associação, que mede a força do grau de relacionamento entre duas 
variáveis, ou seja, mede o grau de correlação (negativa ou positiva) entre duas variáveis. Os autores apontam uma classificação para os resultados obtidos, tendo como correlação, 0,10 até 0,30 (fraco); 0,40 até 0,6 (moderado); 0,70 até 1 (forte), tanto positiva como negativa. No caso dos dados em análise, essa suposição é atendida e todas as correlações são significativas.

Ao analisar os resultados obtidos, pode-se confirmar que há correlação positiva e significativa entre fraca e moderada no alinhamento das dimensões do comprometimento instrumental/calculativo, normativo, afetivo/atitudinal e comprometimento organizacional.

A análise de correlação entre os fatores instrumental/calculativo e comprometimento organizacional apresentaram grau de correlação significativa igual a 0,428 . O resultado pode expressar que o PPR proporciona aos colaboradores um grau de esforço extra, que por sua vez, acaba influenciando no comprometimento organizacional (BECKER, 1960) e vice-versa.

O alinhamento entre normativo e comprometimento organizacional resultou em um grau de correlação significativa de 0,371. A dimensão normativa representa a correlação dos colaboradores com o comprometimento organizacional baseado nas pressões e regras da instituição (WIENER, 1982).

A análise da correlação entre os fatores afetivo/atitudinal e comprometimento organizacional apresentou correlação significativa de 0,424. Maior apego dos colaboradores com as crenças e valores, atrelado ao sentimento de pertencer a instituição, impactam no aumento do comprometimento organizacional (BORGESANDRADE; ABBAD; MOURAO, 2007). Nesse caso, os colaboradores podem ver o PPR como uma recompensa por estarem inseridos e atuantes na instituição. 
A correlação entre os fatores instrumental/calculativo e afetivo/atitudinal apresentou correlação significativa forte de 0,709, o qual remete os esforços realizados pelos colaborados para obter um retorno alinhada às crenças e a cultura da organização (BECKER, 1960; BORGES-ANDRADE; ABBAD; MOURAO, 2007).

O grau de correlação entre os fatores instrumental/calculativo e normativo resultaram em grau de significância forte de 0,797, demonstrando os laços entre os esforços dos colaboradores atrelados às normas e pressões da organização (WIENER, 1982; BECKER, 1960).

O alinhamento que obteve maior grau de significância foram os fatores normativo e afetivo/atitudinal com resultado de 0,818, revelando o apego dos colaboradores à crença e cultura da organização com as regras e pressões da organização (WEINER, 1982; BORGES-ANDRADE; ABBAD; MOURAO, 2007).

Mowday et al. (1982) destaca que o comprometimento organizacional atua como uma força que está relacionada com a identificação e o envolvimento dos colaboradores com a instituição. O autor explica que comumente as correlações entre comprometimento se dão a partir das características pessoais do colaborador, onde o maior comprometimento é associado a maior idade, maior tempo de serviço na organização e maior remuneração.

Após a realização do procedimento da correlação $r$ de Pearson foi realizado o teste de multicolinearidade, por meio dos testes Tolerância e Fator de Inflação da Variância (FIV), apresentado na Tabela 4, com os construtos formados pelas médias de suas variáveis. 
Tabela 4 - Teste tolerância e FIV

\begin{tabular}{|c|c|c|c|c|c|c|c|}
\hline \multirow{2}{*}{ Modelo } & \multicolumn{2}{|c|}{$\begin{array}{l}\text { Coeficientes não } \\
\text { padronizados }\end{array}$} & \multirow{2}{*}{$\begin{array}{l}\text { Coeficiente } \\
\text { s } \\
\text { Padronizad } \\
\text { os }\end{array}$} & \multirow{2}{*}{$\mathbf{t}$} & \multirow{2}{*}{ Sig. } & \multicolumn{2}{|c|}{$\begin{array}{l}\text { Estatística de } \\
\text { Colinearidade }\end{array}$} \\
\hline & B & $\begin{array}{c}\text { Erro } \\
\text { Padrão }\end{array}$ & & & & $\begin{array}{c}\text { Tolerân } \\
\text {-cia }\end{array}$ & VIF \\
\hline 1 (Constant) & 3,021 & 0,327 & & 9,23 & 0,000 & & \\
\hline $\begin{array}{l}\text { Instrumental/Calcul } \\
\text { ativo }\end{array}$ & 0,257 & 0,127 & 0,315 & $\begin{array}{r}2,02 \\
1\end{array}$ & 0,046 & 0,355 & 2,819 \\
\hline Normativo & $-0,100$ & 0,144 & $-0,132$ &,- 693 & 0,490 & 0,237 & 4,226 \\
\hline Afetivo/Atitudinal & 0,237 & 0,125 & 0,309 & $\begin{array}{r}1,89 \\
0\end{array}$ & 0,062 & 0,323 & 3,100 \\
\hline
\end{tabular}

Variável Dependente: COMPROMETIMENTO_ORGANIZACIONAL

Fonte: Dados da pesquisa, 2019.

Os resultados indicam a presença de multicolinearidade aceitável, pois os valores do teste FIV estão entre 1 e 10 e os valores do teste de tolerância estão entre 0,10 e 1.

Posteriormente foi realizado o teste de ausência de autocorrelação serial, através do teste de Durbin-Watson, apresentando na Tabela 5 a seguir.

Tabela 5 - Teste Durbin-Watson

\begin{tabular}{|c|c|c|c|c|c|}
\hline Modelo & $\mathbf{R}$ & $\mathbf{R}^{2}$ & $\begin{array}{l}\mathbf{R}^{\mathbf{2}} \\
\text { ajustado }\end{array}$ & $\begin{array}{l}\text { Erro-padrão da } \\
\text { estimativa }\end{array}$ & Durbin-Watson \\
\hline 1 & 0,465 & 0,217 & 0,191 & 0,51649 & 2,004 \\
\hline
\end{tabular}


a. Preditores: (Constant), INSTRUMENTAL/CALCULATIVO, NORMATIVO, AFETIVO/ATITUDINAL

b. Variável Dependente: COMPROMETIMENTO_ORGANIZACIONAL

Fonte: Dados da pesquisa, 2019.

Os resultados do teste de Durbin-Watson indicam a ausência de autocorrelação serial, pois os valores de estatística próximos a 2 atendem ao pressuposto previsto pela literatura (CORRAR; PAULO; DIAS FILHO, 2012; GUJARATI; PORTER, 2011).

O $\mathrm{R}^{2}$ ajustado da Análise de Regressão, apresentado na Tabela 5, indica que 19,1 \% da variabilidade total do construto "Comprometimento Organizacional" é explicada pelas variáveis independentes consideradas significativas ( $a=5 \%$ ).

A validade global também foi verificada pela análise de variância, conforme apresentada na Tabela 6 a seguir.

Tabela 6 - Análise de variância (ANOVA)

\begin{tabular}{ll|l|l|l|l|l}
\hline Modelo & & $\begin{array}{l}\text { Soma dos } \\
\text { quadrados }\end{array}$ & Graus de Liberdade & Média Quadrática & F & Sig. \\
\hline 1 & Regression & 6,714 & 3 & 2,238 & 8,389 & 0,000 \\
& Residual & 24,275 & 91 & 0,267 & & \\
Total & 30,989 & 94 & & & \\
\hline
\end{tabular}

a. Preditores: (Constant), INSTRUMENTAL/CALCULATIVO, NORMATIVO, AFETIVO/ATITUDINAL

b. Variável Dependente: COMPROMETIMENTO_ORGANIZACIONAL

Fonte: Dados da pesquisa, 2019.

O resultado, apresentado na tabela anterior, foi significativo com sig=0,000; $\mathrm{F}=8,389$, o que confirma a adequação do instrumento ao estudo proposto. Na Tabela 7 a seguir, estão dispostos os resultados da análise de regressão. 
Tabela 7 - Coeficientes

\begin{tabular}{|c|c|c|c|c|c|}
\hline \multirow[t]{2}{*}{ Modelo } & \multicolumn{2}{|c|}{$\begin{array}{l}\text { Coeficientes } \\
\text { não } \\
\text { padronizados }\end{array}$} & \multirow[t]{2}{*}{$\begin{array}{l}\text { Coeficientes } \\
\text { padronizados }\end{array}$} & \multirow[t]{2}{*}{$\mathbf{t}$} & \multirow[t]{2}{*}{ Sig. } \\
\hline & B & $\begin{array}{l}\text { Erro } \\
\text { Padrão }\end{array}$ & & & \\
\hline 1 (Constant) & 3,021 & 0,327 & & 9,234 & 0,000 \\
\hline Instrumental/Calculativo & 0,257 & 0,127 & 0,315 & 2,021 & 0,046 \\
\hline Normativo & $-0,100$ & 0,144 & $-0,132$ & $-0,693$ & 0,490 \\
\hline Afetivo/Atitudinal & 0,237 & 0,125 & 0,309 & 1,890 & 0,062 \\
\hline
\end{tabular}

a. Variável Dependente: COMPROMETIMENTO_ORGANIZACIONAL

Fonte: Dados da pesquisa, 2019.

Conforme os coeficientes apresentados na Tabela 7, os construtos normativo e afetivo/atitudinal não exercem influência significativa sobre o construto dependente comprometimento organizacional. Já o instrumental/calculativo é o construto que exerce influência sobre o construto dependente comprometimento organizacional, pois apresenta influência direta com significância estatística (t=2,021; Sig=0,046), e Beta com importância explicativa de 0,315 sobre a variação comprometimento organizacional.

Dessa forma, pode-se constatar, tomando como base os respondentes do questionário, que o PPR proporciona um comprometimento instrumental/calculativo, ou seja, os colaboradores estão comprometidos com o PPR pelo fato deles trabalharem e se esforçarem em troca de um resultado advindo deste esforço (BECKER, 1960). Por sua vez, Mowday et al. (1982) destaca que o comprometimento instrumental/calculativo possui maior representação em instituições com maiores trocas entre o indivíduo e a organização, onde o colaborador percebe equidade sua contribuição e a recompensa recebida. 
Não obstante, Becker (1960) considera-se que as trocas entre a organização e indivíduo, ao ponto que, o reconhecimento do colaborador por parte da empresa faz com que ele permaneça na organização enquanto houver retornos derivados de seu empenho (BANDEIRA; MARQUES; VEIGA, 2000). Entretanto, baixos índices da dimensão comprometimento afetivo, pode indicar indícios de complicações que merecem alerta do departamento de Recursos Humanos para com os colaboradores da instituição, pois um baixo índice dessa dimensão pode demonstrar que os colaboradores da instituição não possuem um apego às crenças e valores da instituição, o que pode gerar perdas significativas na questão organizacional (MOWDAY et al., 1982).

Os resultados da pesquisa vão de encontro aos estudos de Jones e Pliskin (1988) e Bassi (1995), pois consideraram os programas de PPR como um elemento positivo que acaba elevando a produtividade e o desempenho, se gerenciado corretamente. Ao analisar os resultados da pesquisa de Costa (2002) ao estudar a relação entre o PPR e o comprometimento organizacional, o autor constatou com base nas análises, que para os colaboradores da instituição em estudo, levando em consideração as três associações em relação ao comprometimento organizacional em relação ao PPR, os resultados mais expressivos estão voltados ao instrumental/calculativo.

Ao analisar os dados, pode-se perceber que os resultados da pesquisa possuem certa semelhança aos estudos de Farzan et al. (2008), pois estudaram a questão do PPR em uma empresa de software, onde os colaboradores eram premiados pelo número de conteúdo que incluíam no site, onde os autores constaram que para alcançar o desejo dos colaboradores em receber algo em troca por suas contribuições, uma abordagem a ser utilizada são os mecanismos de recompensa por contribuição ou participação. 
4.2 Análise qualitativa dos dados

Para analisar as respostas das questões abertas do questionário procedeu-se a análise temática. Dos 95 questionários válidos, 72 respondentes escreveram sobre a primeira questão descritiva opcional que se refaria: Este espaço está destinado para que você possa colocar sua opinião pessoal com relação as influências do PPR no seu comprometimento com a Cresol Baser. Das respostas obtidas, pode-se perceber que os colaboradores responderam que sim, ou seja, o PPR de alguma forma contribui para o seu comprometimento com o trabalho realizado na Cooperativa de Crédito Cresol Baser.

Os respondentes descreveram que o PPR motiva a trabalhar mais pois gera um retorno financeiro quando atingidas as metas, e esse retorno acaba possibilitando a realização de sonhos, outros destacam que é um grande incentivo e influência para se trabalhar com qualidade e produtividade. No Quadro 1 apresenta-se recortes das respostas, descrevendo que o PPR tem influência no comprometimento com a Cooperativa de Crédito Cresol Baser.

Quadro 1 - Respostas abertas sobre a influência do PPR no comprometimento

\begin{tabular}{|l|l|}
\hline \multicolumn{1}{|c|}{ RESPONDENTE } & \multicolumn{1}{|c|}{ RESPOSTA } \\
\hline Respondente 01 & "O PPR ajuda sim no comprometimento..." \\
\hline Respondente 15 & "O PPR influencia na dedicação ao trabalho..." \\
\hline Respondente 20 & $\begin{array}{l}\text { "...acredito que com o PPR temos um comprometimento maior em } \\
\text { concluir nossas metas" }\end{array}$ \\
\hline Respondente 25 & $\begin{array}{l}\text { "...ótima ferramenta institucional para aumentar o } \\
\text { comprometimento com as metas estabelecidas pela Cooperativa } \\
\text { de Crédito" }\end{array}$ \\
\hline Respondente 62 & $\begin{array}{l}\text { "O PPR é um dos motivadores a permanecer na Cooperativa de } \\
\text { Crédito..." }\end{array}$ \\
\hline
\end{tabular}

Fonte: Dados da pesquisa, 2019. 
Com base nas respostas, Mowday et al. (1982) discorrem sobre o comprometimento como sendo uma relação onde o colaborador demonstra esforço e trabalho em prol do sucesso da instituição em que trabalha. Observando os estudos de Costa (2002) ao estudar sobre o PPR em uma indústria moveleira do Rio Grande do Sul, pode-se constatar, pela análise qualitativa, que há semelhanças entre os resultados da autora com os resultados dessa pesquisa. Para esse autor, que quantificou os dados da sua pesquisa, $24 \%$ dos respondentes comentaram que o PPR atua como um fator de comprometimento e $20 \%$ dizem que o programa auxilia a caminharem com a indústria e buscarem atingir as metas estabelecidas.

Cinco colaboradores levaram em consideração, no momento de responder à questão, aspectos tanto pessoais como profissionais ao elaborarem as respostas, havendo algumas ponderações que independente de ter ou não o PPR. Nesse sentido, alguns dos respondentes comentaram que o comprometimento com o trabalho seria o mesmo com ou sem o PPR, e que o PPR por si só não influencia no comprometimento, outros nem sabiam da existência do PPR quando começaram a trabalhar na Cooperativa de Crédito em estudo.

No Quadro 2, a seguir, há o recorte das respostas que descreveram que o PPR não gera um impacto no seu comprometimento com a Cooperativa de Crédito Cresol Baser.

Quadro 2 - respostas abertas sobre a influência do PPR no comprometimento

\begin{tabular}{|l|l|}
\hline RESPONDENTE & \multicolumn{2}{|c|}{ RESPOSTA } \\
\hline Respondente & "...mesmo quando não há PPR contínuo \\
13 & comprometido" \\
\hline $\begin{array}{l}\text { Respondente } \\
16\end{array}$ & $\begin{array}{l}\text { "Independente do PPR meu comprometimento com a } \\
\text { empresa é muito forte..." }\end{array}$ \\
\hline Respondente & "Não seria somente o PPR que me faz ser uma \\
\hline
\end{tabular}




\begin{tabular}{|l|l|}
\hline 36 & pessoa comprometida..." \\
\hline $\begin{array}{l}\text { Respondente } \\
\text { Respondente }\end{array}$ & "O PPR pouco influencia no comprometimento por si \\
57 & uma ó é um grande fator..." \\
\hline
\end{tabular}

Fonte: Dados da pesquisa, 2019.

Observando as principais respostas obtidas, percebe-se que o PPR não interfere diretamente no comprometimento de alguns colaboradores. Esse resultado vai de encontro com os resultados da pesquisa de Medeiros e Heidemann (2000) ao estudaram sobre o PPR em um complexo industrial da WEG de Jaraguá do Sul - SC. Por meio das respostas dos participantes e das análises realizadas pelos pesquisadores, foi concluído que o programa não é um dos principais fatores motivacionais e de comprometimento da empresa.

Em relação à segunda questão que indagava aos colaboradores: Descreva algo que você gostaria de destacar que contribui para o comprometimento com a Cresol Baser. Dos 95 questionários válidos, 64 dos colaboradores responderam a questão, destacando vários aspectos que contribuem para o comprometimento de cada um com o seu trabalho. No Quadro 3, segue o recorte de algumas respostas.

Quadro 3 - respostas abertas para outros aspectos que contribuem para o comprometimento

\begin{tabular}{|l|l|}
\hline RESPONDENTE & RESPOSTA \\
\hline $\begin{array}{l}\text { Respondente } \\
01\end{array}$ & "...bom relacionamento e clima organizacional..." \\
\hline Respondente & "Os bons relacionamentos na área de trabalho..." \\
\hline
\end{tabular}




\begin{tabular}{|c|c|}
\hline 05 & \\
\hline $\begin{array}{l}\text { Respondente } \\
18\end{array}$ & $\begin{array}{l}\text { "Reconhecimento, valorização, acolhimento e o } \\
\text { tratamento do funcionário como ser humano" }\end{array}$ \\
\hline $\begin{array}{l}\text { Respondente } \\
80\end{array}$ & $\begin{array}{l}\text { "...líder que saiba valorizar a aproveitar a } \\
\text { diversidade de experiências na equipe. A } \\
\text { integração e comunicação da equipe..." }\end{array}$ \\
\hline $\begin{array}{l}\text { Respondente } \\
81\end{array}$ & $\begin{array}{l}\text { "Clima organizacional positivo, oportunidades de } \\
\text { crescimento pessoal e profissional..." }\end{array}$ \\
\hline
\end{tabular}

Fonte: Dados da pesquisa, 2019.

Analisando as respostas, há grande destaque ao bom relacionamento, reconhecimento, tratamento recebido pelos líderes, valorização pessoal, preocupação com o bem-estar, respeito entre os colegas, união e cooperação entre as equipes, enfim, vários aspectos voltados ao relacionamento e ao convívio em equipe. Nesse caso, isso significa que ter uma boa relação com o companheiro e a equipe de trabalho acaba gerando mais resultados positivos para própria empresa e para o próprio colaborador, pois acaba não existindo atrito e competitividade entre as equipes, muitos destacaram os benefícios, salários, premiações, viagens, estrutura, credibilidade, a história de sucesso da empresa e a política do RH, ou seja, fatores que a empresa através dos seus resultados financeiros pode proporcionar aos seus colaboradores, e muitos desses fatores são básicos, como benefícios e salário. Podese apontar, com base nas respostas da segunda questão, que grande parte dos colaboradores são gratos por trabalharem em uma instituição financeira, como a Cooperativa de Crédito Cresol Baser, pois era um sonho da família e isso por si só já é uma grande motivação para seu comprometimento no trabalho.

Os resultados obtidos na análise dessa questão, também vão de encontro com os resultados obtidos por Medeiros e Heidemann (2000). Os autores constataram em seus estudos que os aspectos que influenciam o comprometimento estão voltados a 
melhoria do clima organizacional, no desempenho, na produtividade e na qualidade do trabalho. Na organização de estudo dos autores, o PPR não motivou os colaboradores, pois não atendeu por completo as expectativas destes, juntamente com o descontentamento das diretrizes do programa.

\subsubsection{Entrevista com Gestora de Recursos Humanos}

De acordo com a gestora de Recursos Humanos, entrevistada na primeira semana de setembro, o PPR foi aprovado pelo Conselho de Administração da Central Cooperativa de Crédito em 12 de novembro de 2009, passando por algumas alterações em sua política nos anos de 2013 e 2017, porém somente a partir do ano de 2011 que passou a ser pago todos os anos.

Dos objetivos firmados entre a instituição e os colaboradores, destacam-se: o melhoramento do desempenho das equipes, atrelando o pagamento de participação nos resultados aos objetivos e metas; o reconhecimento do esforço da equipe na construção dos resultados; desenvolvimento de uma cultura de comprometimento e engajamento em relação aos objetivos; alavancar os negócios e o resultado; incentivar melhorias dos níveis de qualidade e produtividade de todos os colaboradores; e premiar os colaboradores pela participação que eles tiveram nos resultados obtidos pela instituição.

A gestora comentou que os indicadores, metas e suas delimitações, e demais regras de elegibilidade ao PPR, são determinadas pelas estratégias de negócios e comissão de colaboradores. Os indicadores mostram o que o empregador irá avaliar, enquanto a meta é a definição do objetivo que se espera alçar na avaliação. Já a delimitação da meta é o percentual mínimo e máximo a ser atingido da meta definida para cada indicador. Para ser concedido o pagamento do PPR é necessário que sejam cumpridos os percentuais mínimos da meta de cada indicador, que é atingir no mínimo 30\% e no máximo 100\% do resultado financeiro (sobras) e atingir no mínimo 
$80 \%$ e o no máximo $100 \%$ do planejamento comercial. A avaliação do percentual das metas dos indicadores da Cooperativa de Crédito Cresol Baser se dará com o cumprimento do atingimento mínimo das delimitações estabelecidas para as singulares (média).

Em relação aos desafios e resultados da implantação do PPR, a gestora mencionou que "o principal desafio era implantar a cultura de PPR, motivar as pessoas para atingirem suas metas e assim melhorar o resultado financeiro do sistema." Nesse sentido, ela explica que a implantação se iniciou com o intuito de realmente fazer com que os colaborados se comprometessem em trabalhar em prol do crescimento da instituição. Dessa forma, a motivação da Cooperativa de Crédito Cresol Baser em adotar o PPR foi para reconhecer a participação dos colaboradores no crescimento e resultado do sistema.

Indo ao encontro da resposta da gestora, os autores Coopers e Lybrand (1996) enfatizam que as instituições adotam sistemas de remuneração variável e programas de participação com intuito de motivar os colaboradores a buscarem aperfeiçoamento profissional e a mesclar os objetivos pessoais com o da instituição. Através da análise dos dados obtidos nas entrevistas com os gestores de $\mathrm{RH}$, Becker (1998) pode concluir que as instituições referentes ao seu estudo veem o PPR como um diferencial competitivo, uma vantagem na área de Recursos Humanos, caracterizando-o como um instrumento eficaz de gestão.

Sobre as evidências que caracterizam alguma mudança de comportamento do colaborador após a utilização do PPR a gestora explicou que os profissionais passaram a cumprir metas, e todos lutam pelos mesmos objetivos e que isso é bem visível, pois a maioria dos colaboradores está empenhada e dedicada com as metas e objetivos propostos pela instituição. 
Quanto ao alcance das metas e objetivos, e o comprometimento dos colaboradores com o PPR a gestora afirma que houve mudanças após a adoção do PPR. Segundo ela, "sim, todos os anos depois de alcançado os números, outros desafios são impostos". Frisou que os colaboradores "buscam sempre cumprir as metas para alcançar o prêmio máximo de reconhecimento, e pelos pagamentos que realizamos, entendemos que a grande maioria dos empregados estão comprometidos". Sobre os resultados que a instituição tem obtido, nos últimos anos, com o emprego do Programa de Participação nos Resultados foi destacado pela entrevistada que o PPR é um prêmio de reconhecimento que auxilia o processo de atração e retenção de talentos, não sendo a única ferramenta para a retenção dos colaboradores, mas tem auxiliado bastante.

A afirmação da gestora de RH em relação a retenção de talentos, está alinhada aos resultados do estudo de Genari e Macke (2018). Os autores comentam que em um cenário competitivo, é imprescindível que a organização efetue métodos de retenção de colaboradores, tais como: gestão do clima organizacional, sistemas de recompensas e reconhecimento, programas de treinamento, gestão de carreira e avaliação de desempenho. Nesse sentido, entre os meios de obter maior retenção de talentos, a instituição em estudo atua também com o PPR.

Becker (1998) ao estudar as experiências do PPR em uma empresa do Rio Grande do Sul, identificou inicialmente que o foco dos gestores em aderirem ao programa estava centrado em trazer benefícios ao trabalhador. Ao aprofundar as entrevistas, concluiu que, para a organização, a política de participação nos resultados dava mais ênfase na gestão da empresa do que nas vantagens para o trabalhador, pois, destacaram que a distribuição só ocorre quando há resultados financeiro. 


\section{CONSIDERAÇÕES FINAIS}

A partir dos anos 90, começaram a surgir no Brasil, mudanças e sinais que impulsionaram uma maior abertura e flexibilidade na área da gestão organizacional (STONER; FREEMAN, 1995), permitindo que as organizações pudessem implementar programas de participação e demais instrumentos de gestão que pudessem gerar maior engajamento, comprometimento, motivação e conciliação dos objetivos organizacionais e dos objetivos pessoais dos colaboradores.

Esse estudo teve por propósito verificar se o PPR atua como fator de comprometimento, sob a ótica dos colaboradores da Cooperativa de Crédito Cresol Baser de Francisco Beltrão - PR, delimitando os objetivos específicos da pesquisa em: analisar se o PPR atua como um fator de comprometimento dos colaboradores da Cooperativa de Crédito; verificar se o alcance das metas da Cooperativa de Crédito está atrelado ao PPR; averiguar se há outros fatores além do PPR que possam instigar o comprometimento dos colaboradores. Com esse intuito, utilizou-se uma abordagem quali-quanti por meio de aplicação de um questionário para os colaboradores da instituição, para verificar como os respondentes avaliam seu grau de comprometimento em relação ao PPR implementado pela Cooperativa de Crédito Cresol Baser, utilizando um instrumento com escala tipo Likert de 5 pontos, elaborado com base nos estudos de Mowday et al. (1982) e com duas questões abertas. Também foi realizada uma entrevista com uma das Gestoras de RH.

Atendendo ao objetivo proposto, a partir dos dados quantitativos, os resultados da análise de regressão apontam que o PPR atua como um fator de comprometimento com maior influência voltada para a dimensão instrumental/calculativo, evidenciando que os colaboradores se comprometem com a instituição por terem ciência que serão recompensados pelo seu esforço. As dimensões normativo e afetivo/ atitudinal não tiveram significância relativa nos testes de regressão. 
Observando os dados quantitativos e as respostas abertas dos questionários percebe-se que para grande parte (72 de 95) dos colaboradores o PPR atua como um fator de comprometimento, mesmo que para alguns colaboradores (23 de 95) haja outros fatores que instigam o comprometimento (clima organizacional, reconhecimento, valorização, etc.). Entretanto, para alguns respondentes, o PPR não interfere no seu comprometimento com a Instituição. No que diz respeito ao alcance das metas, o estudo demonstrou a partir das questões abertas e da entrevista com a gestora de Recursos Humanos que um dos intuitos da implementação do PPR foi para atingir as metas e alavancar o nível financeiro da instituição, bem como servir de mecanismo de motivação e comprometimento para com os colaboradores.

O estudo possibilitou comparar os resultados com as referências teóricas e demais trabalhos empíricos sobre a temática, o que permitiu maior compreensão em relação ao comprometimento organizacional atrelado ao PPR, bem como identificar algumas divergências entre os resultados da pesquisa com trabalhos empíricos.

Sendo assim, este estudo voltado ao comprometimento organizacional por meio do PPR representa importante contribuição à instituição em estudo, como ao meio organizacional e acadêmico, pois seus resultados podem servir de comparativo as demais pesquisas relacionadas ao tema e que venham a utilizar uma temática ou instrumento de coleta de dados semelhante, podendo até realizar comparativos entre os resultados obtidos. Ademais, contribuiu para aumentar o conhecimento do pesquisador acerca do tema, podendo vir a somar aos demais estudos empíricos sobre essa temática.

As limitações encontradas remetem-se ao fato de ser realizado em uma instituição em específico, onde os resultados não podem ser generalizados. Outra limitação é de que a mensuração por meio de escala pode não evidenciar a realidade estudada. 
Dessa forma, recomenda-se que sejam realizados estudos mais aprofundados em outras instituições ou em segmentos diferentes. Podem ser realizados estudos ligando a questão do comprometimento não somente ao PPR, mas também a outros fatores organizacionais, levando em consideração fatores financeiros e não financeiros, ou então uma comparação entre eles para averiguar o que de fato compromete o colaborador com a instituição a qual trabalha.

Por fim, através do levantamento qualitativo, constatou-se que o PPR tem impacto no comprometimento organizacional, bem como identificou que há outros fatores que contribuem no comprometimento com a instituição. Através da análise de regressão, pode-se apurar que a dimensão instrumental/calculativo tem maior impacto no comprometimento.

\section{REFERÊNCIAS}

ALBUQUERQUE, L. G. de. Estratégias de recursos humanos e competitividade. In: Vieira, M. M. F.; OLIVEIRA, L. M. B. (Orgs.) São Paulo: Atlas, 1999.

ALBUQUERQUE, L. G. de. O papel estratégico de recursos humanos. 1987. 262 f. Tese (Doutorado) - Curso de Administração, Departamento de Administração da Faculdade de Economia, Administração e Contabilidade, Universidade de São Paulo, São Paulo, 1987.

ÁLVARES, A. C. T. Participação nos lucros definida pelos resultados. Revista de Administração de Empresas, v. 39, n. 4, p. 70-77, 1999.

ALVES, L. A. M. Programa de participação nos resultados: um estudo sobre dificuldade e facilidades em três empresas do ramo de beneficiamento de fumo. 2002. Disponível em: https://www.lume.ufrgs.br/handle/10183/2312. Acesso em: 11 mar. 2019. 
BANDEIRA, M. L.; MARQUES, A. L.; VEIGA, R. T. As dimensões múltiplas do comprometimento organizacional: um estudo na ECT-MG. Revista de Administração Contemporânea, 4(2),133157, 2000. doi: 10.1590/S1415-65552000000200008.

BARBETA, P. A. Estatísticas aplicadas às ciências sociais. Florianópolis: UFSC, 1984.

BASSI, M. S. A Participação Dos Trabalhadores nos Lucros das Empresas. 1995. Disponível em: http://bibliotecadigital.fgv.br/dspace/bitstream/handle/10438/4994/1199501417.pdf?sequenc e=1\&isAllowed=y. Acesso em: 10 mar. 2019.

BASTOS, A. V. B. O conceito de comprometimento- sua natureza e papel nas explicações do comportamento humano no trabalho.1994. Disponível em: https://repositorio.ufba.br/ri/handle/ri/1666. Acesso em: 25 jun. 2018.

BARROS, A. R. O. Comprometimento organizacional: um estudo de suas relações com práticas de gestão de pessoas e intenção de permanência. 2007. 145 f. Dissertação (Mestrado Profissional em Administração) - Escola de Administração, Universidade Federal da Bahia, Salvador, 2007.

BECKER, G. V.; RUAS, R. L. Estratégias de comprometimento e planos de participação nos lucros: tendências recentes. Revista de Administração Contemporânea, [s.l.], v. 1, n. 3, p.141161, dez. 1997. FapUNIFESP (SciELO). http://dx.doi.org/10.1590/s141565551997000300008.

BECKER, G. V. Aplicação de Programas De Participação nos Lucros ou Resultados como Estratégia de Comprometimento na Gestão De Recursos Humanos. 1998. Disponível em: https://www.lume.ufrgs.br/bitstream/handle/10183/2204/000270553.pdf?sequence=1. Acesso em: 13 mar. 2019.

BECKER, H. S. Notes on the concept of commitment. The American Journal of Sociology, v. 66, 1960.

BEN-NER, A.; JONES, D.c. Employee Participation, Ownership, and Productivity: A Theoretical Framework. 1995. Disponível em: https://onlinelibrary.wiley.com/doi/abs/10.1111/j.1468232X.1995.tb00387.x. Acesso em: 13 mar. 2019. 
BOHLANDER, G.; SNELL, S.; SHERMAN, A. Administração de Recursos Humanos. São Paulo: Cengage Learning, 2003.

BORGES-ANDRADE, J. E.; ABBAD, G. S.; MOURAO, L. Treinamento, desenvolvimento e educação em organizações trabalho: fundamentos para a gestão de pessoas. Porto Alegre: Artmed, 2007.

BRASIL. LEI N 10.101, DE 19 DE DEZEMBRO DE 2000. Dispõe sobre a participação dos trabalhadores nos lucros ou resultados da empresa e dá outras providências. edição federal, Brasília, DF, 19 dez. 2000. Disponível em: http://www.planalto.gov.br/ccivil_03/leis/l10101.htm. Acesso em: 03 mar. 2019.

BRONDANI, G.; SILVA, T. M. da. Programa de Participação nos Resultados como Fator de Motivação. 2003. Disponível em: https://periodicos.ufsm.br/sociaisehumanas/article/view/1201. Acesso em: 11 maio 2018.

CARVALHO, I. M. V. et al. Cargos, Carreiras e Remuneração. 2. ed. Rio de Janeiro: Editora Fgv, 2011.

CARVALHO, M. C. M. de (Org.). Metodologia Científica: Fundamentos e técnicas. 2. ed. Campinas: Papirus, 1989.

CHIAVENATO, I. Gerenciando pessoas: o passo decisivo para a administração participativa. São Paulo: Makron Books, 1992.

CIRIBELLI, M. C. Como elaborar uma dissertação de mestrado através da pesquisa científica. Rio de Janeiro: 7letras, 2003.

COOPERS; LYBRAND. Remuneração Estratégica: a nova vantagem competitiva. São Paulo: 1996.

CORRAR, L. J.; PAULO, E.; DIAS FILHO, J. M. (Coord.). Análise multivariada: para os cursos de administração, ciências contábeis e economia. 1. ed. São Paulo: Atlas, 2012. 
CORRÊA, D.; LIMA, G. T. Participação dos trabalhadores nos lucros e resultados das empresas: lições da experiência internacional. Rev. econ. contemp. 2006, vol.10, n.2, pp.357388. ISSN 1415-9848. http://dx.doi.org/10.1590/S1415-98482006000200006.

CORREIA NETO, J. F. EXCEL para Profissionais de Finanças: manual prático. 5. ed. Rio de Janeiro: Elsevier, 2007.

COSTA, S. A. A prática das novas relações trabalhistas, por uma empresa moderna. São Paulo: Atlas, 1997.

COSTA, V. M. F. As influências de um programa de participação nos resultados no comprometimento organizacional: o caso de uma empresa gaúcha no ramo moveleiro. 2000. Disponível em: https://repositorio.ufsc.br/handle/123456789/78413. Acesso em: 02 maio 2019.

DANCEY, C. P., REIDY, J. Estatística Sem Matemática para Psicologia: Usando SPSS para Windows. 3. ed. Porto Alegre: Artmed, 2008.

DEDECA, C. S. Racionalização econômica, emprego e relações de trabalho no capitalismo avançado. Campinas: Unicamp, 1997.

DELGADO, M. G. Curso de Direito do Trabalho. 8. ed. São Paulo: LTr, 2009.

DEFOURNEY, J. et al. The effects of workers' participation on enterprise performance. International Journal Of Industrial Organization, [s.I.], v. 3, n. 2, p.197-217, jun. 1985. Elsevier BV. http://dx.doi.org/10.1016/0167-7187(85)90004-9.

DESIDÉRIO, R. Quando a conversa sobre sexo chega à escola. Rio de Janeiro: E-papers, 2010.

DETONI, E. P. T. Gestão plena da remuneração: uma evolução para além de um plano de cargos, salário e carreira. Brasília: Registro Autoral na Fundação Biblioteca Nacional, 2013.

DUBRIN, J. A. Fundamentos do Comportamento Organizacional. São Paulo: Thomson, 2003.

DUTRA, J. S.; HIPÓLITO, J. A. M. Remuneração e recompensas. São Paulo: Atlas, 2012. 
FARZAN, R. et al. Results from Deploying a Participation Incentive Mechanism within the Enterprise. 2008. Disponível em: http://joandimicco.com/publications/chi1231-farzan.pdf. Acesso em: 11 mar. 2019.

FAVERO, L. P. L.; BelfiORE, P. P. Manual de análise de dados: estatística e modelagem multivariada com excel, SPSS e stata. Rio de Janeiro: Elsevier, 2017.

FAVARIM, F. Remuneração e salário: uma abordagem jurídico/administrativa. Revista de Ciências Gerenciais, 2011. Disponível em: http://www.pgsskroton.com.br/seer/index.php/rcger/article/view/2246. Acesso em: 4 maio 2019.

FERNANDES, B. H. R.; BERTON, L. H. Administração Estratégica: da competência empreendedora à avaliação de desempenho. 2. ed. São Paulo: Saraiva, 2012.

FLANNERY, T. P. et al. Pessoas, desempenho e salários: as mudanças na forma de remuneração nas empresas. São Paulo, 1997.

FONSECA, J. J. S. Metodologia da pesquisa científica. 2002. Disponível em: https://books.google.com.br/books?id=oB5x2SChpSEC\&pg=PA20\&dq=pesquisa+quantitativa\& $\mathrm{hl}=\mathrm{pt}-$

BR\&sa=X\&ved=0ahUKEwim0MuFtMDdAhXBkpAKHQuzBwwQ6AEIKDAA\#v=onepage\&q=pesqu isa\%20quantitativa\&f=false. Acesso em: 13 set. 2018 .

FRAGA, L. D. Motivação nas Organizações. Revista da Católica, v. 3, p. 1, 2011.

FRANCO, J. de O. Cargos, Salários e Remuneração. Curitiba: lesde Brasil, 2012.

FRANCO, J. de O. Recursos Humanos: Fundamentos e processos. Curitiba: lesde Brasil S.a., 2008. 122p.

GARRIDO, L. M. Participação nos lucros e resultados: manuais de instrução. São Paulo: Nobel, 1999. 
GENARI, D.; MACKE, J. Gestão Estratégica de Recursos Humanos e Inovação de Produto: Proposições de Pesquisa Relacionadas às Práticas de Atração, Retenção e Desenvolvimento. Gestão e Sociedade, v. 12, n. 33, p. 2508-2540, 2018.

GIL, A. C. Métodos e técnicas de pesquisa social. 6. ed. São Paulo: Atlas, 2008.

GILMAN, N. P. Profit sharing between employer and employee. New York: Houghton, Mifflin and Company, 1891.

GONÇALVES, J. A. T. Metodologia da Pesquisa. 2008. Disponível em: http://metodologiadapesquisa.blogspot.com.br/2008/11/objetivos-gerais-e-especficos.html. Acesso em: 08 maio 2018.

GRESSLER, L. A. Introdução à Pesquisa: Projetos e Relatórios. 2. ed. São Paulo: Loyola, 2004.

GUJARATI, D. N.; PORTER, D. C. Econometria básica. 5. ed. Porto Alegre: AMGH, 2011.

GUSTIN, M. B. S.; DIAS, M. T. F. (Re)Pensando a pesquisa jurídica. 2. ed. Belo Horizonte: del Rey, 2006.

HAIR JR., J. F.; ANDERSON, R. E.; TATHAM, R. L.; BLACK, W. C. Análise multivariada de dados. 5. ed. Porto Alegre: Bookman, 2005.

INFOCOS, I. F. C. S. C. E. Bem-vindo à Cresol. Francisco Beltrão: [s.n.], 2016.

JOÃO, P. S. Participação nos lucros ou resultados das empresas. São Paulo: Dialética, 1998.

JONES, D. C.; PLISKIN, J. L. The Effects of Worker Participation, Employee Ownership and Profit Sharing on Economics Performance: A Partial Review. 1988. Disponível em: https://papers.ssrn.com/sol3/papers.cfm?abstract_id=191169. Acesso em: 12 mar. 2019.

LAKATOS, E. M.; MARCONI, M. A. Fundamentos de metodologia científica.? $6 a$ ed. - $4^{\mathrm{a}}$ reimpressão - São Paulo: Atlas, 2007.

LANDIM, P. M. B. Análise estatística de dados geológicos. 2. ed. São Paulo: Unesp, 2003. 
LOBOS, J. Participação dos trabalhadores nos lucros da empresa. São Paulo: Centro de Pesquisa em Relações do Trabalho, 1990.

LOPES, J. O fazer do trabalho científico em Ciências Sociais Aplicadas. Recife: Universitária da Ufpe, 2006.

MALHOTRA, N. K. Pesquisa de marketing: uma orientação aplicada. 6. ed. Porto Alegre: Bookman, 2012.

MANZINI, E. J. A entrevista na pesquisa social. Didática, São Paulo, v. 26/27, p. 149-158, 1991.

MATHIS, R. L.; JACKSON, J. H. Human resource management. 10. ed. Mason: SouthWestern/Thomson, 2003.

MARRAS, J. P. (Org.). Gestão estratégica de pessoas: conceitos e tendências. São Paulo: Saraiva, 2010.

MARINAKIS, A. E. A participação dos trabalhadores nos lucros e resultados das empresas no Brasil: um instrumento para acelerar a restruturação necessária. 1997. Disponível em: http://www.scielo.br/pdf/rae/v37n4/a07v37n4.pdf. Acesso em: 12 mar. 2019.

MARTÍN, F. A.; ROMERO, F. P. M.; SÁNCHES, G. G. Human resource management as a field of research: British Journal of Management. 2008. Disponível em: https://www.researchgate.net/publication/247637453_Human_Resource_Management_as_a_F ield_of_Research. Acesso em: 10 abr. 2019.

MARTINS, S. P. Direito do Trabalho. 24. ed. São Paulo: Atlas, 2008.

MASCARENHAS, A. O. Gestão estratégica de pessoas. São Paulo: Cengage Learning, 2009.

MEDEIROS, S.; HEIDEMANN, F. G. Participação nos resultados e clima organizacional favorável ao desempenho da empresa Weg S.A. Revista de Negócios, Blumenau, v. 5, p.364-375, out. 2000.

METZGER, S. L. Profit Sharing in 38 large companies. Evanston: Profit Sharing Research Foundation, 1975. 
MEYER, J. P. et al. Affective, Continuance, and Normative Commitment to the Organization: A Meta-analysis of Antecedents, Correlates, and Consequences. 2002. Disponível em: https://www.sciencedirect.com/science/article/abs/pii/S0001879101918421. Acesso em: 09 maio 2019.

MEYER, J. P.; ALLEN, N J.A three-component conceptualization of organizational commitment. $2001 . \quad$ Disponível em: https://www.sciencedirect.com/science/article/abs/pii/105348229190011Z. Acesso em: 06 maio 2019.

MILKOVICH, G. T.; BOUDREAU, J. W. Administração de Recursos Humanos. 8. ed. São Paulo: Atlas, 2009.

MOREIRA, P. A. et al. Modelo de Remuneração na Gestão de Pessoas: A Estruturação Tradicional de Cargos e Salários Ainda Pode Trazer Benefícios? . Future Studies Research Journal: Trends and Strategies, v. 8, n. 3, p. 3-23, 2016.

MOTA, R. S. Motivação e liderança e a importância da remuneração neste processo. 2013. Disponível em: https://books.google.com.br/books?id=9BRRBQAAQBAJ\&pg=PA8\&dq=Motiva\%C3\%A7\%C3\%A3 o+nas+organiza\%C3\%A7\%C3\%B5es\&hl=ptBR\&sa=X\&ved=0ahUKEwjgobH_y5ziAhXNIbkGHZO5 CDIQ6AEIVjAI\#v=onepage\&q=Motiva\%C3\%A7\%C3\%A3o\%20nas\%20organiza\%C3\%A7\%C3\%B5 es\&f=false. Acesso em: 18 abr. 2019.

MOTTA, W. H. Remuneração Variável: "stock options”, valor econômico agregado, participação nos lucros ou resultados e benefícios flexíveis. 2009. Disponível em: https://www.aedb.br/seget/arquivos/artigos05/6_REMUNERACAO\%20variavel.pdf. Acesso em: 03 mar. 2019.

MOWDAY, R. T. et al. Employee Organization Linkages: a psychology of commitment, absenteism and turnover. New York: Academic Press, 1982.

NASCIMENTO, A. M. Iniciação ao Direito do Trabalho. São Paulo: LTr, 2009. 
OLIVEIRA, A. C. Benefício mais desejado é participação nos lucros. 2014. Disponível em: https://exame.abril.com.br/carreira/para-todos-os-bolsos/. Acesso em: 05 maio 2018.

OLIVEIRA, A. J. de; SUPERTI, E.Participação nos lucros e resultados - PLR: um estudo sobre as ferramentas de remuneração variável da administração participativa. 2006. Disponível em: http://revistaadmmade.estacio.br/index.php/revistahorus/article/viewFile/3935/1756. Acesso em: 09 mar. 2019.

OLIVEIRA, S. L. de. Tratado de metodologia científica. São Paulo: Pioneira. 1997.

PASQUALI, L. Psicometria: teoria e aplicações. Brasília: UnB, 1997.

PICCOLI, J. C. J. Normalização para trabalhos de conclusão em educação física. 2. ed. Canoas: Ulbra, 2006.

PONTES, B.R. A competitividade e a remuneração flexível. São Paulo: LTr, 1995.

POUTSMA, E.; HENDRICKX, J.; HUIJGEN, F. Employee Participation in Europe: In Search of the Participative Workplace. Economic And Industrial Democracy, [s.I.], v. 24, n. 1, p.45-76, fev. 2003. SAGE Publications.http://dx.doi.org/10.1177/0143831×03024001599.

RAMPAZZO, Lino. Metodologia Científica: para alunos dos cursos de graduação e pósgraduação. 3. ed. São Paulo: Loyola, 2005.

REGO, A.; SOUTO, S. Comprometimento organizacional: um estudo luso-brasileiro sobre a $\begin{array}{lllll}\text { importância da } & \text { justiça. } & \text { Disponível }\end{array}$ http://www.anpad.org.br/admin/pdf/enanpad2002-cor-569.pdf. Acesso em: 20 abr. 2019.

RENDER, B.; STAIR JR, R. M.; HANNA, M. E. Análise Quantitativa para Administração: com Excel e Pom-QM para Windows. São Paulo: Artmed, 2010.

REY, F. G. Pesquisa qualitativa em psicologia: caminhos e desafios. São Paulo: Thomson, 2005.

RICHARDSON, R. Pesquisa social: métodos e técnicas. São Paulo: Atlas, 1989.

RIBEIRO, A. de L. Gestão de Pessoas. São Paulo: Savaira, 2006. 
ROBBINS, P. S. Comportamento Organizacional. $11^{\text {a }}$ ed. São Paulo: Pearson Prenticce Hall, 2005.

RODRIGUES, W. A.; NETO, M. T. R.; FILHO, C. G. As influências na motivação para o trabalho em ambientes com metas e recompensas: um estudo no setor público. Revista de Administração Pública, v. 48, n. 1, p. 253-273, 2014.

ROSSI, C. A. V.; SLONGO, L. A. Pesquisa de satisfação de clientes: o estado da arte e proposição de um método brasileiro. Revista de Administração Contemporânea, São Paulo. v. 2, n. 1, p. 101-125, Jan.-Abr. 1998.

SCHWAAB, M.; PINTO, J. C. Análise de dados Experimentais I: Fundamentos de Estatística e Estimação de Parâmetros. Rio de Janeiro: E-papers, 2007.

SCHWARTZ, S. H. (1992). Universals in the content and structure of values: Theoretical advances and empirical tests in 20 countries. In M. P. Zanna (Ed.), Advances in experimental social psychology, Vol. 25, pp. 1-65, 1992. San Diego, CA, US: Academic Press. http://dx.doi.org/10.1016/S0065-2601(08)60281-6.

SILVA, A. L. C. da. Introdução à Análise de dados. 2. ed. Rio de Janeiro: E-papers, 2011.

SILVESTRE, A. L. Análise de Dados e Estatística Descritiva. São Paulo: Escolar, 2007.

STAKE, R. E. Pesquisa Qualitativa: estudando como as coisas funcionam. São Paulo: Artmed, 2011.

STEERS, R.; MOWDAY, R. Organizational Commitment, Job Satisfaction, and Turnover among $\begin{array}{llll}\text { Psychiatric Technicians. } 1974 . & \text { Disponível }\end{array}$ https://www.researchgate.net/publication/263917217_Organizational_Commitment_Job_Satisf action_and_Turnover_Among_Psychiatric_Technicians. Acesso em: 11 mar. 2019.

STONER, J. A. F.; FREEMAN, R. E. Administração. 5.ed., Rio de janeiro: Prentice Hall, 1995.

TAMAYO, A.; PASCHOAL, T. A relação da motivação para o trabalho com as metas do trabalhador. Revista de Administração Contemporânea, [s.I.], v. 7, n. 4, p.33-54, dez. 2003. FapUNIFESP (SciELO). http://dx.doi.org/10.1590/s1415-65552003000400003. 
TELLES JUNIOR, H. O. Como escrever seu artigo: Explicações simples. Porto Alegre: Plus, 2019

TRIVIÑOS, A. N. S. Introdução à pesquisa em ciências sociais: a pesquisa qualitativa em educação. São Paulo: Atlas, 1987.

TUMA, F. Participação dos trabalhadores nos lucros ou resultados das empresas: incentivo à eficiência ou substituição dos salários?. São Paulo: LTr, 1999.

ULRICH, D. Os campeões de recursos humanos: inovando para obter os melhores resultados. São Paulo: Futura, 1998.

VEIGA, L. D. S. et al. Comprometimento Organizacional no Terceiro Setor: O Caso de uma Organização Tradicionalista Gaúcha. Revista de Carreiras e Pessoas, v. 9, n. 1, p. 63-83, 2019.

VERGARA, S. C. Gestão de pessoas. 3. ed. ampl. São Paulo: Atlas, 2003.

WIENER, Yoash. Commitment in organizations: a normative view. Academy Management Review. 1982. Disponível em: https://journals.aom.org/doi/abs/10.5465/AMR.1982.4285349. Acesso em: 06 maio 2019.

YIN, R. K. Pesquisa qualitativa do início ao fim. Porto Alegre: Penso, 2016.

ZONATTO, V. C. S.; SILVA, A.; GONÇALVES, M. Influência da Motivação para o Trabalho no Comprometimento Organizacional. Revista de Administração IMED, v. 8, n. 1, p. 169-190, 2018. 
